ORALPRESENTATIONABSTRACTS

\section{OP-01 \\ CASTICIN: A PROMISING CANDIDATE TO DEVELOP A STEM CELL TARGETED STRATEGY IN AML TREATMENT}

Tuğba Erkmen ${ }^{1}$, Belgin Sert Serdar ${ }^{1}$, Halil Ateş ${ }^{2}$, Pembe Keskinoğlu ${ }^{3}$, Ayşe Semra Koçtürk ${ }^{4}$

${ }^{1}$ Department of Biochemistry, Health Sciences Institute, Dokuz Eylül University, Faculty of Medicine, Izmir, Turkey

${ }^{2}$ Oncology Institute, Dokuz Eylül University, Faculty of Medicine, Izmir, Turkey

${ }^{3}$ Department of Public Health, Dokuz Eylul University, Faculty of Medicine, Izmir, Turkey

${ }^{4}$ Department of Biochemistry, Dokuz Eylül University, Faculty of Medicine, Izmir, Turkey

Purpose: Acute myeloid leukemia is the most common form of acute leukemia with genetic and epigenetic heterogeneity. Although current chemotherapeutics provide successful remission, 5-year survival rates are still low. Insufficiency of targeting leukemia stem cells is considered as the main obstacle that cause drug resistance and relapse. Phytochemicals, especially polyphenols remain a promising source for targeted drug research. Studies showed that Casticin, which is a predominant polyphenolic component of the fruit of Vitex trifolia, has antiproliferative effects on leukemic cells, but its effects on leukemic stem cells are still unclear. In this study, we aimed to investigate the antiproliferative capacity of Casticin on acute myeloid leukemia stem-like (KG1a) cell line and its parental (KG1) cell line comparison with healthy peripheral blood mononuclear (PBMC) cell line.

Method: The antiproliferative effects of Casticin on cells and IC50 values were determined by MTT test. The effects of Casticin on caspase 3/7 activity, apoptosis, and necrosis in cells were evaluated by flow cytometry and TUNEL assays.

Results: $2 \mu \mathrm{M}$ Casticin treatment for $24 \mathrm{~h}$ was increased apoptosis, caspase $3 / 7$ activation in KG1 $(27,2 \%$; 17,30\%; $\mathrm{p}<0,01)$ KG1a $(21,6 \% ; 11,35 \% ; \mathrm{p}<0,01)$ with relatively low necrosis $(1,4 \% ; 0,3 \%)$ compared to their control groups. TUNEL assay also confirmed Casticin-induced apoptosis in KG1 $(22,3 \%$; $<<0,05)$, KG1a cells $(19,03 \%$; $\mathrm{p}<0,05)$. There were no significant changes in apoptosis $(10,6 \%)$, caspase $3 / 7$ activity $(0,24 \%)$, necrosis $(0,6 \%)$ of $\mathrm{PBMC}$ compared to its control group.

Conclusion: Casticin has the capacity to induce apoptosis in both leukemia stem-like and parental cells without significantly affecting healthy cells. Therefore, we think that Casticin can be a promising compound to develop novel therapeutic strategies for final AML treatment.

Keywords: apoptosis, acute myeloid leukemia, casticin, cancer stem cells

\section{OP-02 \\ THE ROLE OF LACTATE DEHYDROGENASE- RELATED MODIFICATION OF TUMOR METABOLISM ON APOPTOSIS AND EPITHELIAL MESENCHIMAL TRANSITION (EMT) IN EXPERIMENTAL PROSTATE CANCER}

Cağrı Cakıcı ${ }^{1}$, Benay Daylan², Şule Ayla ${ }^{2}$, Hilal Eren Gözel ${ }^{3}$, Pakize Yiğit ${ }^{4}$, Elif Yavuz Dokgöz ${ }^{5}$, Türkan Yiğitbaş $1^{1}$

${ }^{1}$ Department of Biochemistry, School of Medicine, Istanbul Medipol Univ ersity, Istanbul, Turkey

${ }^{2}$ Department of Histology and Embriology, School of Medicine, Istanbul Medipol University, Istanbul, Turkey

${ }^{3}$ Regenerative and Restorative Medicine Research Center (REMER), Health Sciences and Technology Research Institute (SABITA), Istanbul Medipol University, Istanbul, Turkey

${ }^{4}$ Department of Biostatistics and Medical Informatics, School of Medicine, Istanbul Medipol University, Istanbul, Turkey

${ }^{5}$ Department of Biochemistry, Faculty of Pharmacy, İstinye University, Istanbul, Turkey

Aim: LDH-A is the form of LDH found in cancer cells, which is the main regulator of anaerobic glycolysis. Increased LDH-A activity; promotes tumor growth and metastasis, increases migration and invasion. The aim of this study is to investigate the effects of the combination of LHD-A inhibitor and Docetaxel on apoptosis, oxidative stress and EMT in the experimental prostate cancer model.

Method: In this study, 50 male C57BL/6 mice were used. Each experimental group (1- control group; 2- prostate cancer control group; 3- docetaxel; 4- LDH-A inhibitor; 5- LDH-A inhibitor + docetaxel) was divided into five groups of 10 mice each. CK18-M30, lactate and total antioxidant capacity, total oxidant status and oxidative stress index values were calculated from serum samples. TUNEL staining for apoptosis analysis, western blot and qPCR analysis for EMT were performed from tumor tissue samples. Hematoxylin-eosin staining was performed in the liver and periodic acid schiff staining was performed in the kidney tissues.

Findings: When the lactate results were examined, it was seen that the LDH-A inhibitor reversed the Warburg effect. Docetaxel and LDH-A inhibitor + Docetaxel treatment groups significantly increased oxidative stress and apoptosis $(\mathrm{p}<0.05)$. When the effect on EMT was examined, it was observed that the LDH-A inhibitor + Docetaxel group increased the expression of E-cadherin and significantly decreased the expression of $\mathrm{N}$-cadherin $(\mathrm{p}<0.05)$. Also, expression of Snail, Slug and Twist transcription factors were decreased $(p<0.05)$. 
$3^{\text {rd }}$ International Cancer and Ion Channels Congress 2021

Result: When LDH-A inhibitor is added to Docetaxel, which is conventionally used in the treatment of prostate cancer, apoptosis and oxidative stress increased and EMT decreased. In this study, it was revealed for the first time that combined therapy with LDH-A inhibitör + docetaxel has been a potential target for the development of new anticancer agents.

Keywords: apoptosis, emt, ldh-a inhibition, prostate cancer

\section{OP-03}

INVESTIGATION OF MIR-639 AND MIR-641
EXPRESSION LEVELS IN THE TISSUES OF
COLORECTAL CANCER PATIENTS

$\underline{\text { Rușen Avșar }}^{1}$, Türkan Gürer ${ }^{1}$, Alper Aytekin²

${ }^{1}$ Department of Biology, Faculty of Science, Gaziantep University, Gaziantep, Turkey

${ }^{2}$ Department of General Surgery, Faculty of Medicine, Gaziantep University, Gaziantep, Turkey

Objective: Colorectal cancer is one of the most common human cancers worldwide. MicroRNAs are small noncoding RNAs about $17-25$ nucleotides. It is known that miRNAs play an important role in various biological processes such as development, differentiation and proliferation, and are molecules that can regulate the development and progression of cancer. It has been reported that microRNAs play a regulatory role in colorectal carcinogenesis. The purpose of this study is to investigate the expression levels of miR-639 and miR-641 in the tissues of patients diagnosed with colorectal cancer.

Method: The study included 59 patients who were operated in Gaziantep University Şahinbey Research and Practice Hospital, Department of General Surgery and diagnosed with colorectal cancer. The material of the study consisted of tumor and adjacent healthy tissues of these patients. The study was approved by the local ethics committee of Gaziantep University (Ethical approved number: 2019/420). RNA was isolated from tissue samples and cDNA synthesis was performed from isolated RNAs by Reverse Transcriptase PCR method. miR-639 and miR641 expression levels were determined by quantitative Real Time PCR method. RNU6 was used as internal control miRNA.

Results: As a result of the study, miR-639 and 641 expression levels were significantly downregulated in tumor tissues compared to adjacent normal tissues $(\mathrm{p}<0.05)$.

Conclusion: Considering the findings obtained from the study, it can be said that miR-639 and miR-641 play a tumor suppressor role in the pathogenesis of colorectal cancer and may be new candidate biomarkers that can be used in the diagnosis.

Acknowledgments: This study was supported by the
Scientific Research Projects Managements Unit of Gaziantep University (Project No: FEF. ALT. 19. 28).

Keywords: Colorectal cancer, expression, miR-639, miR641, tissue.

\section{OP-04 \\ DIFFERENT FRACTIONS OF SALIX BABYLONICA L. LEAF EXTRACT HAVE DIFFERENT EFFECTS ON INSULIN RELEASE IN INS-1 CELLS}

Dilara Aylar $^{1}$, Fatma Kazdal², Fatemeh Bahadori², Ayşe Karatuğ Kaçar ${ }^{1}$

${ }^{1}$ Department of Biology, Faculty of Science, Istanbul University, Istanbul, Turkey

${ }^{2}$ Department of Pharmaceutical Biotechnology, Faculty of Pharmacy, Bezmialem Vakif University, Istanbul, Turkey

\section{Background/Aim}

Salix babylonica L. is a member of family Salicaceae. Insulinoma which is a tumor originating from pancreatic beta cells shows higher secretion compared to normal pancreatic beta cell. Our study was aimed to investigate calcium, potassium and sodium ions that play an important role in insulin secretion and Akt protein that are important in the insulin mechanism in INS-1 cells treated to Salix babylonica L. leaf extract.

\section{Materials and Methods}

We used INS-1 cells. Ethyl Acetate (EtOAc), Butanol $(\mathrm{BuOH})$ and water $(\mathrm{H} 2 \mathrm{O})$ fractions were isolated from leaf of Salix babylonica L. and applied exogenously to INS-1 cells. The cell viability was measured using WST1. Glucose-stimulated insulin secretion was measured using ELISA kit. Insulin level in both cell lysate and cell secretion, AKT and p-AKT levels in cell lysate by western blotting, Ins1, Ins2, AKT gene expressions by qRT-PCR were also studied. Calcium, sodium and potassium levels were analyzed in both cell lysate and cell secretion by autoanalyzer.

\section{Results}

All extract fractions were decrease the cell viability. INS1 cells treated with $\mathrm{BuOH}$ fraction are functional insulinproducing beta-cells $(\mathrm{p}<0.001)$, while INS-1 cells treated with EtOAc $(\mathrm{p}<0.001)$ and $\mathrm{H} 2 \mathrm{O}(\mathrm{p}<0.001)$ fractions are not functional insulin-producing beta-cells. Insulin levels decreased in both cell lysate $(\mathrm{p}<0.001$ for $\mathrm{BuOH}, \mathrm{p}<0.01$ for $\mathrm{H} 2 \mathrm{O})$ and secretions $(\mathrm{p}<0.01)$. Ins1 $(\mathrm{p}<0.01$ for $\mathrm{BuOH}$, $\mathrm{p}<0.05$ for $\mathrm{H} 2 \mathrm{O})$, Ins2 $(\mathrm{p}<0.001$ for $\mathrm{H} 2 \mathrm{O})$ and $\mathrm{AKT}$ $(\mathrm{p}<0.001$ for $\mathrm{BuOH}, \mathrm{p}<0.05$ for $\mathrm{H} 2 \mathrm{O})$ gene expression levels were significantly increased. Calcium $(p<0.05$ for $\mathrm{BuOH}$ in lysate, $\mathrm{p}<0.05$ for $\mathrm{BuOH}$ and $\mathrm{p}<0.001$ for $\mathrm{H} 2 \mathrm{O}$ in secretion) and potassium levels $(\mathrm{p}<0.05$ for $\mathrm{BuOH}$ and $\mathrm{p}<0.001$ for $\mathrm{H} 2 \mathrm{O}$ in lysate, $\mathrm{p}<0.05$ for $\mathrm{H} 2 \mathrm{O}$ in secretion) changed in both cell lysate and secretions, while sodium levels $(\mathrm{p}<0.01$ for $\mathrm{BuOH}, \mathrm{p}<0.001$ for $\mathrm{H} 2 \mathrm{O}$ ) changed in cell lysate. 
Conclusions: Salix babylonica L. leaf extract of different fractions caused cell death in INS-1 cells. Different fractions have different effects on pancreatic beta cell function. The increase of calcium increases insulin secretion in functional beta cell. However, the secretion of insulin in cells with high calcium levels and normal functions was decreased in $\mathrm{BuOH}$ group in this study. Thus, it could be hypothesized that the active substances in the $\mathrm{BuOH}$ fraction which cause cell death and damage, plays a primary role in insulin secretion. In $\mathrm{H} 2 \mathrm{O}$ and EtOAc groups, it can be thought that insulin secretion changes due to cell dysfunction and cell death occurs accordingly.

Keywords: Calcium, Insulin, Insulinoma, Potassium, Salix babylonica L., Sodium

\section{OP-05 \\ THE EFFECTS OF TARGETED DINUTUXIMAB BETAMONOCLONALANTIBODY ON PANCREATIC BETA CELL TOXICITY}

\author{
Ayse Karatuğ Kaçar ${ }^{1}$, Zelal Adıgüzel ${ }^{2}$ \\ ${ }^{1}$ Department of Biology, Faculty of Science, Istanbul \\ University, Istanbul, Turkey \\ ${ }^{2}$ Department of Molecular Biology and Genetics, Faculty of \\ Medicine, Basic Medical Sciences, Koc University, Istanbul, \\ Turkey
}

\section{Background / Aim}

INS-1 cells are tumor cells with characteristic features of pancreatic beta cells. Dinutuximab beta is the first monoclonal antibody that used for the treatment of neuroblastoma. The aim of this study is to investigate the effects of Dinutuximab beta, whose effect is unknown in pancreatic beta cell tumor (INS-1 cells), based on the similarity between pancreatic beta cells and neurons.

\section{Materials and Methods}

We have used insulinoma INS-1 cells. Dinutuximab beta (Qarziba $\left.{ }^{\circledR}\right)$ which presented by EUSA Pharma was used for the experiments. The cell cytotoxicity was induced by Streptozotocine (STZ). Dinutuximab beta was administered to the cells following STZ administration and before STZ administration. The cell viability was determined with WST1 assay. Reactive oxygen species were measured by using dichlorofluorescein diacetate as spectrophotometric. The cells were marked with DAPI to indicate apoptotic markers (nuclear condensation and fragmentation) with confocal microscope. GLUT2 (Glucose transporter 2), IR (Insulin receptor), Ins1 and Ins2 expression levels were analyzed with q-RT-PCR.

\section{Results}

The INS-1 cells proliferated with administration of Dinutuximab beta alone $(\mathrm{p}<0.05$ for $24 \mathrm{~h}, \mathrm{p}<0.01$ for $48 \mathrm{~h}, \mathrm{p}<0.001$ for $72 \mathrm{~h}$ ). The result of Dinutuximab beta administered following STZ administration, resulted in more cell death $(p<0.001$ for $24 h, 48 h$ and $72 h$ ), increased ROS levels ( $p>0.05$ for $24 h, p<0.001$ for $48 h$ and $72 h$ ), GLUT2, Ins1, Ins2 gene expression levels $(\mathrm{p}<0.001$ for $24 \mathrm{~h}, 48 \mathrm{~h}$ and $72 \mathrm{~h})$ and decreased IR gene expression levels $(\mathrm{p}<0.001$ for $24 \mathrm{~h}$ and $72 \mathrm{~h}, \mathrm{p}>0.05$ for $48 \mathrm{~h}$ ) than Dinutuximab beta administered before STZ administration. After Dinutuximab beta was administered to the cells following STZ administration, the cells predominantly died via apoptosis showing cytoplasmic condensation and DNA fragmentation after 24 and 48 hours.

\section{Conclusions}

As a results, Dinutuximab beta can show its effect after occurred toxicity. Time-dependent cell death increases as a result of administration of Dinutuximab beta after toxicity induced by STZ. In cytotoxic conditions, Dinutuximab beta is an important monoclonal antibody in terms of performing the death of insulinoma cells. Its use as a chemotherapeutic agent in tumor treatment should be supported by in vivo studies.

Keywords: Cell Death, Dinutuximab beta, Immunotherapy, Insulinoma INS-1 cells, Oxidative Stress.

\section{OP-06}

ALTERNATIVE METHODS ON THE NUMERICAL SOLUTION OF THE AVASCULAR TUMOR MODEL

$\underline{\text { S1la Övgü Korkut Uysal }}{ }^{1}$, Neslişah İmamoğlu Karabaş ${ }^{3}$, Yasemin Başbınar ${ }^{2}$

${ }^{1}$ Department of Engineering Sciences, Izmir Katip Celebi University, Izmir, Turkey

${ }^{2}$ Department of Translational Oncology, Dokuz Eylul University, Izmir, Turkey

${ }^{3}$ Izmir Institute of High Technology, Department of Mathematics, Izmir, Turkey

Objective: Cancer, one of the most challenging health problems overall, comprises various processes: tumorigenesis, angiogenesis, and metastasis. Attempting to understand the truth behind this complicated disease is one of the common objectives of many experts and researchers from different fields. To provide deeper insights any prognostic and/or diagnostic scientific contribution to this topic is so important. The focus point of the current study is the avascular tumor growth model which is the earliest stage of tumor growth from a mathematical point of view. The essential objective is to present alternative methods for approximating the solution of the mathematical model of avascular tumor growth.

Methods: To do so, the continuum mathematical model of the avascular tumor growth described by Sharrett and Chaplin has been taken into account. To obtain the numerical schemes the central difference method has been used in the spatial coordinates. On the other hand, two different techniques, the 4th order Runge-Kutta method (RK4) and the three-stage strongly-stability preserving Runge-Kutta method (SSPRK3), have been studied for the temporal domain. This discretization techniques brings the originality of the study. 
Results: The prescribed model has been solved by the proposed methods. The numerical results are discussed from both mathematical and biological aspects. The biological compatibility of the methods is supported by various figures. Besides biological outputs, the accuracies of the methods have been studied, as well. Furthermore, the computational rate of convergence of the given methods has also been presented.

Conclusion: All reported results are evidence that the presented schemes are applicable for solving such models. Moreover, all exhibited figures have provided the biological compatibility of the methods. It is concluded that the quiescent cells which are one of the most mysterious cells in clinics tend to become proliferative for the selected parameters.

Keywords: Avascular Tumor Growth, Numerical Simulation, Mathematical Biology

\section{OP-07 \\ PROTON PUMP INHIBITORS AND CANCER}

Deniz Tuna Edizer, Zeynep Akçalı, Asım Leblebici, Sıla Övgü Korkut, Ender Berat Ellidokuz

Dokuz Eylül Üniversitesi, Onkoloji Enstitüsü, Translasyonel Onkoloji AD, İzmir, Türkiye

Objective: Proton pump inhibitors (PPIs) are widely used to suppress gastric acid secretion. They are mainly used for gastroesophageal reflux disease, peptic ulcer, erosive gastritis and prevention of gastrointestinal bleeding. PPIs belong to the family of ATPase and especially P-ATPase and V-ATPase types regulate intracellular as well as extracellular acid equilibrium. The main aim of the current study is to present the existing literature putting forth the relation between cancer with both the use of PPIs and proton pumps from positive and negative aspects.

Method: To perform an objective study various types of proton pumps and their relation between cancer have been taken into account. For up to date review, the studies has been considered in the time range from 2011 to 2021 via various databases (PubMed, Scopus and Google Scholar).

Results: $\mathrm{H}+\mathrm{K}+$ ATPase, located within the gastric parietal cells, is one of the most important examples of P-ATPases. However, irregularities of the V-type ATPase were reported to be associated with carcinogenesis and to be seen mostly in highly invasive cancers. Proton pump and cancer interaction may be related to V-type ATPases. PPIs may be associated with the development of metaplasia in the gastric corpus mucosa secondary to parietal cell loss and a causative factor for carcinoid tumors. From another perspective, PPIs decrease the acidic character of the tumor microenvironment and accentuate the effectiveness of cancer treatment. However, they may represent a relatively important security issue although the association with cancer development is not clear yet.

Conclusion: In this systematic review, the relation of the proton pump and its inhibitors with cancer has been introduced, in detail. The findings of the literature review along with criticism were presented.

Keywords: carcinogenesis, cancer, proton pumps, proton pump inhibitors.

\section{OP-08}

\section{TRPM8-RAP1A INTERACTION INHIBITS PROSTATE CANCER CELL ADHESION AND MIGRATION}

Giorgia Chinigò $^{1}$, Guillaume Grolez ${ }^{2}$, Madelaine Audero ${ }^{2}$, Alexandre Bokhobza ${ }^{2}$, Michela Bernardini $^{1}$, Julien Cicero ${ }^{3}$, Robert Alain Toillon ${ }^{3}$, Anna Rita Cantelmo², Marc Lensink ${ }^{4}$, Jerome De Ruyck ${ }^{4}$, Alessandra Fiorio Pla ${ }^{1}$, Dimitra Gkika ${ }^{3}$ ${ }^{1}$ Department of Life Sciences and Systems Biology, University of Torino, 10123 Torino, Italy

${ }^{2}$ Inserm, U1003 - Phycel - Physiologie Cellulaire, University of Lille, F-59000 Lille, France

${ }^{3}$ CNRS, INSERM, CHU Lille, Centre Oscar Lambret, UMR 9020-UMR 1277-Canther-Cancer Heterogeneity, Plasticity and Resistance to Therapies, University of Lille, F-59000 Lille, France

${ }^{4}$ CNRS, UMR 8576 - UGSF - Unité de Glycobiologie Structurale et Fonctionnelle, University of Lille, F-59000 Lille, France

Aim: Emerging evidence indicates that TRPM8 channel plays an important role in prostate cancer ( $\mathrm{PCa}$ ) progression, by impairing the motility of these cancer cells. TRPM8 expression in $\mathrm{PCa}$ was shown to be regulated by steroid hormones and receptor signaling and indeed, it results down-regulated in metastatic androgen-independent PC3 cells. Here, we reveal a novel facet of PCa motility control via direct protein-protein interaction of the channel with the small GTPase, Rap1A.

Methods: The functional interaction was assessed in PC3 cells by active Rap 1 pull-down assays and live-cell imaging experiments. Molecular modeling analyses allowed the identification of four putative residues involved in the interaction of the two proteins. Mutation of these sites followed by GST-pull-down, co-immunoprecipitation and PLA experiments confirmed their importance in the interaction and their functional role was further studied by adhesion and migration assays on PCa cells.

Findings: TRPM8 inhibits $\mathrm{PCa}$ cell migration and adhesion by intracellularly trapping Rap1A in its inactive form (Rap1 N17A), thereby preventing its activation at the plasma membrane. Residues E207 and Y240 in the sequence of TRPM8 and Y32 in that of Rap1A are critical for the interaction between the two proteins. In particular, 
$3^{\text {rd }}$ International Cancer and Ion Channels Congress 2021

PC3 overexpressing TRPM8 with the double mutations E207A Y240A have shown a reduced interaction with the inactive form of Rap1A and, concomitantly, a less prominent inhibition of cell adhesion and migration with respect to those overexpressing TRPM8 wt.

Result: Our data shed light on a new role for TRPM8 that goes beyond its channel function and involves a direct protein-protein interaction with the small GTPase Rap1A, crucial in mediating cell migration and adhesion. This study deepens our knowledge on the mechanism through which TRPM8 would exert a protective role in metastatic PCa thus providing new insight on its possible use as a new therapeutic target in $\mathrm{PCa}$ treatment.

Keywords: prostate cancer, TRPM8, Rap1A, migration, adhesion

\section{OP-09 \\ EFFECTS OF GANODERMA LUCIDUM IN DU-145 CELL LINE}

Seymanur Yilmaz Tasci ${ }^{1}$, Yesim Yeni², Sidika Genc ${ }^{2}$, Ahmet Hacimuftuoglu ${ }^{2}$

${ }^{1}$ Ataturk University, Faculty of Medicine, Physiology Department, Erzurum

${ }^{2}$ Ataturk University, Faculty of Medicine, Medicinal Pharmacology Department, Erzurum

Aim: Prostate cancer is the most common noncutaneous cancer in men worldwide and remains a significant medical problem. Ganoderma lucidum(GL) is a kind of mushroom, and is known as Reishi. GL has been used for promoting good health, perpetual youth, vitality. GL executes the anti-proliferative, pro-apoptotic, anti-metastatic, antiinflammatory, anti-oxidant effects. In this study, it was aimed to evaluate effects of GL extract in DU-145 cell line as the aspect of cell viability, total-oxidant and anti-oxidant status.

Methods: DU-145 cell line were cultured in appropriate medium and cells were seeded $(5 \times 103$ cells/per-well $)$ in 96 well plates. After $24 \mathrm{~h}$ of growth in medium, the cells were treated with various concentrations of GL extract (7.81$1000 \mu \mathrm{g} / \mathrm{mL}$ ) for $24 \mathrm{~h}$. Cell growth and viability were done by the MTT-assay. The stored medium was used for total oxidant and total anti-oxidant status with using commercial kits. Results was evaluated using One-way-Anova, posthoc tests were done with LSD.

Results: According to the findings, it was found that GL extract showed an anti-proliferative effect in the dose ranges of $1000-31.25 \mu \mathrm{g} / \mathrm{mL}$ compared to the control group in the cell viability test $(\mathrm{p}<0.05)$. When the total antioxidant status was evaluated, a significant increase in antioxidant activity was observed at a dose of $125 \mu \mathrm{g} / \mathrm{mL}$ compared to the control group $(\mathrm{p}<0.05)$. When the total oxidant status was evaluated, a significant decrease was observed at all doses compared to the control group $(\mathrm{p}<0.05)$.

Discussion: GL extracts were found to have an antiproliferative effect in the DU145 cell-line in wide dose range. When the antioxidant activity were evaluated, GL extract showed antioxidant activity in only one dose. On the other hand, GL extract shows reduced oxidant activity in all doses. Finally, GL, reishi mushroom, may be a promising agent in cancer treatment.

Keywords: Ganoderma lucidum, DU145, oxidantantioxidant status

\section{OP-10}

\section{HIGH miR-142-3p EXPRESSION IN PERIPHERAL BLOOD OF PATIENTS WITH OVARIAN CARCINOMA}

Yasmin Gider, Xhariqa Jabbarli, Gamze Uyaroğlu, Şeref Buğra Tunçer, Demet Akdeniz Ödemiş, Büşra Kurt, Seda Kılıç, Özge Şükrüoğlu Erdoğan, Betül Çelik, Hülya Yazıcı Department of Basic Oncology, Division of Cancer Genetics, Oncology Institute, Istanbul University, Fatih, Istanbul 34093, Turkey

Objectives: The fact that ovarian cancer manifests itself in the late stage and is characterized by a poor prognosis, is caused death in the majority of cases. miRNAs being as the biomarker candidates in diagnosis, and their use in treatment as the inhibitors of the molecules mimicking the miRNA showed that they may be used as the new therapeutic target and agents. Present study aims to determine the effect of expresion level of miR-142-3p in ovarian cancer patients.

Material-Methods: We detected with our group in our prior study conducted with disconcordant ovarian cancer twins that many miRNA molecules were different in ovarian cancer compared with the molecules in healthy sibling. The expression level of miR-142-3p that was selected from the miRNAs detected in the previous study was compared, and investigated in a wider ovarian cancer group, and in healthy control group. miR-142-3p expression level was investigated using the real-time PCR method in the present study involving 147 patients, and 100 healthy control group. The differences in the expression levels of miR-142$3 p$ detected in the peripheral blood lymphocytes of ovarian cancer patients, and healthy control were statisticaly evaluated.

Results: The expression level of miR-142-3p was detected to have increased 3.11 fold in ovarian cancer patients compared with the levels in healthy controls, and the difference was statistically significant (p:0.00). We suggest that this microRNA showing high expression promoted the oncogenesis of ovarian cells by behaving such an oncogene. miR-142-3p expression level, and the clinical data,diagnosis, and family histories were analysed in details. 
Conclusions: These results suggest that miR-142-3p that was found significantly increased in the peripheral blood samples of ovarian cancer patients compared with the healthy controls might be used as a sensitive, noninvasive biomarker in the early diagnosis, and treatment and follow up of ovarian cancer.

Keywords: Ovarian cancer, miR-142-3p expression, biomarker

\section{OP-11 \\ PROGNOSTIC IMPACT OF 18F-FDG PET/CT IN PRESURGICAL LYMPH NODE STAGING OF NSCLC}

\section{Gamze Tatar}

University of Health Sciences, Istanbul Bağcilar Training and Research Hospital, Department of Nuclear Medicine

Purpose: This study was aimed to explore the role and prognostic significance of 18F-FDG (Fluorine-18 fluorodeoxyglucose)/ PET/CT (Positron Emission Tomography/Computed Tomography) in the assessment of patients with NSCLC (Non small cell lung cancer) and assess the presurgical initial staging by using metabolic parameters in patients with mediastinal lymph node metastasis of NSCLC.

Materials-Methods: 60 patients with NSCLC were scanned on the PET/CT system. Primary tumour, pathological mediastinal lymph nodes and disease related areas were described, FDG uptake patterns were evaluated. Semiquantitative analysis of FDG uptake was performed and SUVmax (maximum standardized uptake value) were measured from the lymph nodes. Presurgical 18F-FDG $\mathrm{PET} / \mathrm{CT}$ results and post operative definitive pathological diagnosis were compared to correlate PET results with clinicopathological variables.

Results: Metastatic lymph nodes were identified in 52 $(86,6 \%)$ of the 60 tumours. 18F-FDG PET/CT showed $92,1 \%$ sensitivity, $64,2 \%$ specificity and $85 \%$ diagnostic accuracy. False negative rate was $7,8 \%$, false positive rate was $55 \%$. False-negative and N0 staged patients had primary tumors that were lower SUVmax and adenocarcinomas when compared with false-positive and nodal metastatic ones.

Conclusions: 18F-FDG PET/CT has a good diagnostic performance for the detection of mediastinal nodal metastasis in patients with NSCLC. In addition, 18F-FDG $\mathrm{PET} / \mathrm{CT}$ may help to select the patients that will profit from surgery and improve prognosis.

Keywords: 18F-FDG PET/CT, NSCLC, nodal metastasis

\section{OP-12 \\ LOXblock-1 REGULATES ANTICANCERACTIVITY ON GLIOBLASTOMA VIA SEMAPHORINS}

\section{Fatih Kar}

Faculty of Engineering and Natural Sciences, Kutahya Health Science University, Kutahya, Turkey

Aim: Glioblastoma (GBM) is one of the most frequent malignant brain tumors, accounting for more than $15 \%$ of all primary central nervous system and brain neoplasms. Semaphorin family proteins are being studied in cancer studies. In this study, we aimed to investigate the effects of LOXblock-1, a 12/15 lipoxygenase inhibitor, on U251 cells via the semaphorin signaling pathway.

Methods: Cell viability was determined by MTT test and apoptotic effects were determined by measuring BAX, BCL, Caspase 3-9. The effect of LOXblock-1 on the expression levels of apoptotic and cell proliferation genes in U251 cells was studied by real-time PCR.

Findings: In this study, LOXblock-1 showed anticancer activity against the U251 cell line. The viability of U251 cells was significantly reduced in a dose-dependently $(p<0.001)$. Bax expressions of apoptosis-associated proteins were increased in cells treated with LOXblock-1, while expression of the antiapoptotic Bcl-2 was decreased, while SEMA3A was induced.

Results: These results provided in vitro evidence for the antitumor, specifically apoptotic effects of LOXblock-1 via the semaphorin signaling pathway

Keywords: lipoxygenase, glioblastome, apoptosis, SEMA3A.

\section{OP-13}

\section{COMBINED EFFECTS OF PTEROSTILBENE AND SODIUM OXAMATE ON BREAST CANCER ENERGY METABOLISM}

Elif Yavuz Dokgöz ${ }^{1}$, Çağrı Çakıcı², Ezgi Daşkın³, Şeyma Çimen $^{4}$, Yasemin Başbınar ${ }^{3}$, Türkan Yiğitbaşı ${ }^{2}$

${ }^{1}$ Istinye University, Faculty of Pharmacy, Department of Biochemistry, Istanbul, Turkey

${ }^{2}$ Istanbul Medipol University, School of Medicine, Department of Medical Biochemistry, Istanbul, Turkey

${ }^{3}$ Dokuz Eylül University, Institue of Oncology, Izmir, Turkey

${ }^{4}$ Istanbul Medipol University, Research Institute for Health Sciences and Technologies, Istanbul, Turkey

Aim: The aim of the study is to show how when we use Pterostilbene in combination with an LDH-A inhibitor, Sodium Oxamate, it will affect the altered energy metabolism in breast cancer cells. 
$3^{\text {rd }}$ International Cancer and Ion Channels Congress 2021

Methods: MDA-MB-231 and MCF-7 breast cancer cell lines were used. Glycolytic and mitochondrial functions of the cells were monitored using Seahorse XF96 extracellular flux analyser. Extracellular acidification rate and oxygen consumption rate were assessed in an assay based on microfluorimetric detection. The Energy Phenotype Analysis gives the orientation of the cellular energy phenotype towards the glycolytic pathway or mitochondrial oxidative phosphorylation system (OXPHOS) after drug/inhibitors are administered to the cells via OCR and ECAR parameters.

Results: According to Glycolytic Stress Analysis, when we compared the glycolic capacity ratios in MCF-7 and MDA-MB-231 cell lines, a significant decrease was observed in the MCF-7 cell line in the combination group. Metabolic orientations of the MCF-7 cell line were examined during stress, and it was observed that the metabolic orientations of the combination group during stress were significantly energetic compared to the negative control. In the MCF-7 cell line, the Sodium oxamate was found to be more energetic than the negative control when their metabolic orientations were compared during stress.

Conclusion: We evaluated the anti-cancer effect of sodium oxamate and pterostilbene and their combination treatment on MDA-MB-231 and MCF-7 cell lines via energy metabolism. The combination of these two promising agents for cancer therapy has resulted much better than sodium oxamate and pterostilbene alone on both cell lines. According to cell energy phenotype results, the $\mathrm{O} 2$ consumption rate of $\mathrm{MCF}-7$ found higher than MDA-MB-231 which proves the Pasteur phenotype of MCF-7 cell line.

This study was supported by TUBITAK Project Number 219S069 and Istanbul Medipol University Project Number 2019/05 BAP.

Keywords: Breast Cancer, Energy Metabolism, OXPHOS, Warburg Effect

\section{OP-14 \\ LOW CONCENTRATION BORAX ENHANCES THE CYTOTOXIC EFFECT OF TEMOZOLOMIDE IN U87 GLIOBLASTOMA CELLS}

\section{Ceyhan Hacığlu}

Department of Medical Biochemistry, Faculty of Medicine, Duzce University, Duzce, Turkey

Aim: Glioblastoma is one of the most common primary malignant brain tumors with its high invasiveness and poor prognosis. As a promising DNA alkylating agent in the treatment of glioblastoma, temozolomide (TMZ) can cross the blood-brain barrier and cause tumor cell death. Borax, as a boron derivative, can suppress tumor cell proliferation by showing both cytotoxic and genotoxic effects through oxidative and antioxidant mechanisms. In this study, we investigated whether low concentration of borax increase the cytotoxic effects of TMZ in U87 glioblastoma cells.

Methods: U87 cells were treated with 0, 5, 10, 20, 40, 80,160 and $320 \mu \mathrm{M}$ TMZ concentrations for 24 hours. Next, we determined the cytotoxic effects and the IC50 concentration of TMZ. We also investigated the effect of low concentration borax $(5 \mu \mathrm{M})$ on U87 cell viability. To examine the single and combined effects of borax and TMZ on U87 cells, we measured the glutathione (GSH), malondialdehyde (MDA), caspase 3 (CASP3) and cytochrome c (CYC) levels by ELISA.

Results: TMZ caused a concentration-dependent decrease in cell viability in U87 cells. In U87 cells treated with TMZ concentrations $(0-320 \mu \mathrm{M})$ for 24 hours, we determined that the IC25, IC50 and IC75 concentrations of TMZ were $62.7,110.6$ and $178.3 \mu \mathrm{M}$, respectively. There was no statistically significant decrease in cell viability in U87 cells treated with $5 \mu \mathrm{M}$ borax for 24 hours $(\mathrm{p}>0.05)$. TMZ+borax treatment caused significantly a greater decrease in GSH levels in U87 cells compared to TMZ treatment $(\mathrm{p}<0.05)$. Similarly, TMZ+borax treatment induced a further increase in MDA, CAPS3 and CYC levels in U87 cells compared to TMZ treatment $(p<0.05)$.

Conclusion: Our results demonstrated the importance of borax in preventing resistance to TMZ during treatment, as well as providing alternative strategies for the glioblastoma treatment.

Keywords: Borax, glioblastoma, temozolomide, U87 cells

\section{OP-15}

\section{ANTIPROLIFERATIVE EFFECTS OF VALPROIC ACID IN HepG2 HEPATOCELLULAR CANCER CELLS VIA FERROPTOSIS SIGNALING PATHWAY}

Ceyhan Hacioğlu, Fatih Davran

Department of Medical Biochemistry, Faculty of Medicine, Duzce University, Duzce, Turkey

Aim: Hepatocellular carcinoma (HCC) is the most common primary liver malignancy and ranks third in cancer-related deaths. There is no effective treatment for $\mathrm{HCC}$, which is usually diagnosed at a late stage and has a poor prognosis with liver dysfunctions. Ferroptosis is an iron-dependent non-apoptotic cell death pathway in which the lipid peroxidation process is central. Valproic acid (VPA) is an antiepileptic and hepatotoxic drug that acts as a histone deacetylase inhibitor. In this study, we investigated the cytotoxic effects of VPA on HCC treatment through ferroptosis. 
Methods: Human hepatocellular carcinoma cells (HepG2) were treated with VPA ranging from $0.5 \mu \mathrm{M}$ to $16 \mu \mathrm{M}$ for 24 hour followed by 3-(4,5-dimethylthiazole, 2-yl)2,5-diphenyl tetrazolium bromide (MTT) analysis to determine its cytotoxic concentrations. Ferroptosis-related glutathione (GSH), glutathione peroxidase 4 (GPX4), malondialdehyde (MDA) and acyl-CoA synthetase longchain family member 4 (ACSL4) levels in VPA-treated HepG2 cells were measured by ELISA method.

Results: Cell viability in HepG2 cells treated with 0.5 , $1,2,4,8$, and $16 \mu \mathrm{M}$ VPA concentrations decreased by $2.4 \%, 15.7 \%, 39.2 \%, 88.6 \%$, and $97.1 \%$, respectively. In biochemical analyzes, IC25 $(3.11 \mu \mathrm{M})$ and IC50 $(6.25 \mu \mathrm{M})$ concentrations of VPA and $4.75 \mu \mathrm{M}$ VPA concentration were used as intermediate dose. MDA and ACSL4 levels increased in a concentration-dependent manner in VPA-treated HepG2 cells. On the other hand, increasing concentrations of VPA caused a decrease in GSH and GPx4 levels.

Conclusion: Our results showed that VPA treatment suppressed proliferation in HepG2 cells by inducing ferroptosis. Although VPA is promising in the treatment of $\mathrm{HCC}$, further studies are needed to investigate its long-term effects in different HCC cell lines.

Keywords: Ferroptosis, hepatocellular, valproic acid

\section{OP-16 \\ REVERSIBLE INHIBITOR OF p97, DBeQ IMPAIR THE TUMORIGENIC ABILITY OF BREAST CANCER CELLS}

\section{$\underline{\text { Yalçın Erzurumlu }}$}

Department of Biochemistry, Faculty of Pharmacy, Suleyman Demirel University, Isparta, Turkey

Aim: Breast cancer is the most common type of cancer diagnosed in women and is the second cause of cancerrelated mortality in women worldwide. Many different strategies have been developed for the treatment of breast cancer, which exhibits biological and molecular heterogeneity. However, the need for the development of alternative treatment approaches continues today. Recent studies suggest that therapeutic approaches targeting the members of protein-quality control mechanism localized in the endoplasmic reticulum (ER) are promising for various cancer types including breast cancer.

ER-associated degradation (ERAD) is a key protein quality control mechanism and is responsible for the selective degradation of malformed proteins. ERAD regulates the steady-state levels of numerous tumor suppressors and oncogenic proteins associated with the tumorigenic process. As a sophisticated mechanism, ERAD consists of many critical modules including substrate recognition, retrotranslocation and ubiquitination, proteasomal degradation. Especially, p97/VCP, a key mediator of the retrotranslocation step of ERAD, is suggested as a strong potential cancer target.

In this study, we investigated the effects of p97/VCP inhibition by $\mathrm{DBeQ}$, which is a selective and reversible p97/VCP inhibitor, on the carcinogenic abilities of breast cancer cells such as proliferation, invasion-migration and colony formation.

Method: In this study, we investigated the effects of DBeQ on the tumorigenic ability of MCF-7 cell line by in vitro techniques including cell proliferation, invasion, migration and colony formation methods. For this purpose, WST-1 assay, matrigel-coated boyden chamber assay, scratching assay and plate formation assays were performed.

Results: Our results indicated that suppression of the enzymatic activity of p97/VCP by DBEQ significantly decreased tumorigenic properties of MCF7 cells (approximately 40-50\% for each assay) including proliferative rate, invasive/migrative capacity and colonial formation abilities.

Conclusion: In conclusion, our findings suggest that targeting the members of ER-localized protein-quality control may be promising alternative treatment approaches to be developed for breast cancer.

Keywords: Breast Cancer, DBeQ, p97/VCP, Tumorigenesis

\section{OP-17 \\ EVALUATION OF ANTIBIOTIC USE AMONG CANCER PATIENTS IN AN ONCOLOGY HOSPITAL: A RETROSPECTIVE STUDY}

$\underline{\text { Filiz Yarimcan }}^{1}$, Ayşe Istanbullu Tosun ${ }^{1}$, Abdullah Ercan Arzuhal $^{2}$

${ }^{1}$ Istanbul Medipol University, Department of Medical Microbiology, Istanbul,Turkey

${ }^{2}$ Esenler Medipol University Hospital, Clinical Laboratory, Istanbul, Turkey

Cancer patients are at high risk of infections. This study aimed to assess the bacterial profile, resistance ratios, and antibiotic use in cancer patients receiving chemotherapy in Istanbul Medipol University Oncology Hospital, Turkey, through a retrospective study covering 50 patients whose specimens were sent for culture.

The medical records of the cancer patients from January 2021 to July 2021 were retrospectively reviewed for infections and the use of antibiotics. Fifty patients with a total of 85 episodes of infection were included.

We detected bacterial growth in $44 \%(n=37)$ of the cases. The most commonly isolated microorganisms were Klebsiella pneumoniae, Escherichia coli, and 
Acinetobacter baumannii from blood and urine samples. The antibiotic resistance rates reported for aminoglycosides, fluoroquinolones, third-generation cephalosporins and carbapenems in Klebsiella pneumoniae were $46 \%, 25 \%$, $33 \%$, and $25 \%$, respectively. The resistance ratios were lower in Escherichia coli, and there was no susceptible antibiotic in the case of Acinetobacter baumannii. The lowest resistance ratios were obtained for piperacillintazobactam, which was the most frequently used in these patients.

The infections with gram-negative organisms predominate. The empirical therapy applied in our hospital seems to be very appropriate regarding the culture and antibiotic susceptibility results.

Keywords: Infections, antibiotics, trends

\section{OP-18}

\section{THE POTENTIAL ROLE OF SMALL VCP INTERACTING PROTEIN (SVIP) IN ADRENOCORTICAL CARCINOMA}

$\underline{\text { Recep İlhan }}^{1}$, Sinem Yılmaz ${ }^{2}$, Yalçın Erzurumlü ${ }^{3}$, Petek Ballar Kırmızıbayrak ${ }^{1}$

${ }^{1}$ Department of Biochemistry, Faculty of Pharmacy, Ege University, 35100 Bornova-İzmir, Turkey

${ }^{2}$ Department of Bioengineering, Faculty of Engineering, University of Alanya Aladdin Keykubat, Antalya, 07400, Turkey; Department of Biochemistry, Faculty of Pharmacy, Ege University, Bornova, 35100, Izmir, Turkey ${ }^{3}$ Department of Biochemistry, Faculty of Pharmacy, Suleyman Demirel University, Isparta, Turkey

Objectives: Adrenocortical carcinoma is a rare, aggressive tumor originating from the adrenal cortex region and affects between 0.7 million and 2 million people per year with a median survival rate is 3.21 years. The endoplasmic reticulum-mediated degradation pathway (ERAD), a mechanism important for proteostasis, plays a role in the pathophysiology of various diseases including some cancer types. Small VCP Interacting Protein (SVIP) is the first identified endogenous inhibitor of ERAD. Here, we aimed to examine the effects of SVIP protein on adrenocortical carcinoma cell proliferation, apoptosis, and cell cycle progress.

Materials-Methods: Lipofectamine 3000 was used to manipulate protein expression levels either by overexpression or silencing. The proliferation rate of H295R cells was monitored using a real-time cellular analysis system (xCELLigence) measuring impedancebased signals. The effect of SVIP levels on cell cycle progress and apoptosis was investigated by flow cytometry. Finally, caspase-7 and -9 levels, which are widely used as apoptosis markers, were investigated by Western Blot.

Results: Cell index-based growth curves were obtained through the RTCA analysis software. It was observed that the increase in SVIP expression levels caused a dosedependent decrease in cell proliferation, but silencing of SVIP enhanced proliferation. Flow cytometry analysis reflected that SVIP overexpression shifts cells to apoptosis in a dose-dependent manner.

Our results also revealed that the levels of cleaved caspase -7 and -9 expression were enhanced by SVIP overexpression. Lastly, cell cycle analysis suggested that there is no significant relationship between cell cycle and SVIP expression levels.

Conclusions: Overall, our results suggest that inhibition of ERAD via SVIP may be a novel therapeutical approach for adrenocortical carcinoma.

Acknowledgement: This study was supported by TUBITAK-SBAG-116S444.

Keywords: adrenocortical carcinoma, apoptosis, H295r, proliferation, SVIP

OP-19

SYNTHESIS OF NOVEL TRIAZOLE MOLECULES AND INVESTIGATION OF THEIR APOPTOTIC EFFECTS ON GLIOBLASTOMA MULTIFORME CELLS

\section{Elif Beyza Koç, Bilgesu Onur Sucu}

Istanbul Medipol University, Research Institute for Health Sciences and Technologies (SABITA), Center of Drug Discovery and Development, Istanbul, Turkey

Aim: Glioblastoma multiform (GBM) is the most aggressive subclass of brain tumors. While the anticancer effects of caffeic acid phenethyl ester (CAPE), one of the active components of propolis, have been proven in many articles, very few studies have been done on its effects on GBM. The aim of this study was to synthesize new CAPE analogs containing 1,2,4-triazole and to investigate their anticancer effects on GBM cell lines.

Method: Cell viability analysis was performed on the synthesized molecules in three different GBM cell lines by Cell Titer-Glo. To investigate whether the molecule, which is more active than CAPE, triggers apoptosis in LN229 cells, the level of cPARP protein was examined by western blot method. DNA fragments that were broken during apoptosis were shown with the Apoptotic DNA Ladder assay, and migration ratio was measured by scratch assay.

Results: It was observed that the synthesized 6 molecules were more potent than CAPE in GBM cell lines. While the IC50 values of our reference molecule CAPE were found to be higher than $100 \mu \mathrm{M}$ on these cells, the IC50 values of $\mathrm{C} 4$, the most active molecule, were found to be $42.91 \mu \mathrm{M}$, $33.89 \mu \mathrm{M}$, and 
$3^{\text {rd }}$ International Cancer and Ion Channels Congress 2021

$57.02 \mu \mathrm{M}$ in U87, T98G, and LN229 cells, respectively. And the $\mathrm{C} 4$, had a less cytotoxic on healthy human mesenchymal stem cells compared to CAPE. In western study, cPARP levels were significantly increased in drugtreated cells. Also in LN229 cells treated with C4 for 48 hours, it was observed that DNA breaks and inhibition of cell migration.

Conclusion: In the light of all studies, C4's inducing apoptosis with more active results in GBM cells, possible anti-metastatic properties, and low toxicity in healthy cells compared to CAPE suggest that it may be a promising drug candidate for GBM cell lines. This study was supported by Tübitak as Project 1002(Project No: 119Z116).

Keywords: Anticancer activity, Caffeic acid phenethyl ester (CAPE), Glioblastoma multiform (GBM), Novel heterocyclic CAPE analogs

\section{OP-20 \\ THE EFFECTS OF DIFFERENT PARTS EXTRACTS OF COLCHICUM SPECIOSUM STEVEN IN DU145 CELL LINE}

Seymanur Yilmaz Tasci ${ }^{1}$, Songul Karakaya ${ }^{2}$, Yesim Yeni ${ }^{3}$, Sidika Genc ${ }^{3}$, Ahmet Hacimuftuoglu ${ }^{3}$

${ }^{1}$ Ataturk University, Faculty of Medicine, Physiology Department, Erzurum

${ }^{2}$ Ataturk University, Faculty of Pharmacy, Department of Pharmaceutical Botany, Erzurum.

${ }^{3}$ Ataturk University, Faculty of Medicine, Medicinal Pharmacology Department, Erzurum.

Aim: Prostate cancer is common cancer in men. Because therapeutic options are limited, the development of new therapeutic approaches is needed. Colchicum speciosum (CS) is flowering plant, native to mountainous areas of norther Turkey. In this study flower and corm extracts of CS is studied for evaluating the effects in DU145 cell-line.

Methods: Colchicum speciosum was gathered from Erzurum and dried corms and flowers extracted with methanol. Human-prostate-carcinoma-cells(DU145) were cultured in appopriate medium until they reached confluence. Cells were seeded at a density of $5 \times 103$ cells/ per-well, grown for $24 \mathrm{~h}$ and then cells exposed to a range of concentrations of CS flower and corm extracts (1000$7.81 \mu \mathrm{g} / \mathrm{mL}$ ), incubated for $24 \mathrm{~h}$. MTT test gives a measure of cell number/proliferation/survival/toxicity/viability. Total-oxidant, total anti-oxidant status were done using medium with commercial kits. The results were evaluated with One-Way-Anova and posthoc test was done with LSD.

Results: According to the MTT test, antiproliferative effects were observed in the dose ranges of 1000-15.62 $\mu \mathrm{g} /$ $\mathrm{mL}$ of CS flower extract and 1000-31.25 $\mu \mathrm{g} / \mathrm{mL}$ of bulbus extract $(p<0.05)$. When the total antioxidant activity was examined, it was found that CS flower extract showed a significant increase in the dose ranges of 125-15.62 $\mu \mathrm{g} /$ $\mathrm{mL}(\mathrm{p}<0.05)$. In the total oxidant state, a significant decrease was observed in the $250-(31.25-7.81) \mu \mathrm{g} / \mathrm{mL}$ dose range of CS flower extract $(\mathrm{p}<0.05)$. In Bulbus extract, while an increase was observed in oxidant activity at doses of 1000$500 \mu \mathrm{g} / \mathrm{mL}$, a significant decrease was observed at a dose of $31.25 \mu \mathrm{g} / \mathrm{mL}(\mathrm{p}<0.05)$.

Discussion: Different extracts of CS were found to have an antiproliferative effect on the DU-145 cell-line. When the oxidant-antioxidant status of this effect were evaluated, bulbus extract increased the oxidant activity at high doses, while the both extracts decreased the oxidant activity in the low dose range. CS extracts may be a therapeutic agent in cancer treatment.

Keywords: Colchicum speciosum, DU145 cell line, cancer

OP-21

PRELIMINARY STUDY: DETERMINATION OF TARGET GLYCOPROTEINS BY PROTEOMIC METHOD IN LIVER METASTASIS BREAST TUMOR

Nebiye Pelin Türker $^{1}$, Elvan Bakar ${ }^{2}$, Saffet Çelik $^{1}$

${ }^{1}$ Trakya University Technology Research Development Application and Research Center, Center/Edirne

${ }^{2}$ Trakya University Faculty of Pharmacy, Department of Basic Pharmacy, Merkez/Edirne

Glycans, which are the main components of the cell membrane, perform important functions in signal transduction, cell-cell and extracellular matrix interactions. Recent studies have shown that glycan alterations in malignant cells play important roles in various stages of tumor progression. Glycans regulate different aspects of tumor progression such as cell proliferation, invasion and metastasis. Many approved clinical cancer biomarkers and therapeutic targets are in the form of glycoproteins. Glycosylation changes are universal markers of malignant transformation and tumor progression in human cancer, occurring in all cells. Therefore, investigation of target glycans is very important in terms of cancer metastasis and disease progression. Within the scope of this preliminary trial study; First, metastatic liver and healthy liver tissues developed due to breast tumor formed with Erclich acid were homogenized in a tissue homogenizer (in the experiment, 6 balb-c albino mice in total were used). Homegenized tissues, by adding appropriate chemicals, respectively; were subjected to denaturation, alkylylation, trypsinization and purification processes and analyzed by LC-QTOF instrument. Analysis results were evaluated using Searchquie and PeptideShacker program interfaces. In the control group; It was determined that $\alpha-\mathrm{N}$ acetylgalactosaminide, $\alpha-2,6$-sialytransferase- 3 on the 3 rd chromosome and Fructose-bisphosphate aldolase B on the 4th chromosome were not found in liver metastasis breast tumors. 
In the liver metastasis group, Dolichyldiphosphooligosaccharide-protein glycosyltranferase subunit 2 protein on the 2 nd chromosome was not found in the control group. Glycoproteins are the most widely used serological biomarkers for clinical diagnosis, monitoring of progression and prognosis of disease relapse in cancers. Today, there is a need for timely diagnosis of cancer, identification of risks, and development of new strategies for treatment. Evaluation of different glycoproteins as biomarker candidates in liver metastasis breast tumor suggests that it will constitute a potential resource for clinical studies.

Keywords: Cancer, Metastasis, Glycan, Glycoprotein

\section{OP-22}

\section{EVALUATION OF ANTICANCER EFFECTS OF NOVEL B-HYDROXY KETONES ON U87 CANCER CELLS}

$\underline{\text { Serife } \text { Yerlikaya }^{1} \text {, Hatice Başpınar Küçük }}{ }^{2}$, Gökhan Kantürk $^{2}$, Tülay Yıldız ${ }^{2}$, Mustafa Guzel ${ }^{3}$

${ }^{1}$ Istanbul Medipol University Vocational School of Health Services Department of Medical Laboratory Techniques,Kavacik Campus, Kavacik-Beykoz/ ISTANBUL 34810, Turkey/Faculty of Medicine Regenerative and Restorative Medicine Research Center, Istanbul/Turkey

${ }^{2}$ Istanbul University-Cerrahpasa, Faculty of Engineering, Department of Chemistry, Organic Chemistry Division, Avc1lar/ISTANBUL 34320, Turkey

${ }^{3}$ Istanbul Medipol University, International School of Medicine, Department of Medical Pharmacology,Kavacik Campus, Kavacik-Beykoz/ISTANBUL 34810, Turkey/ Faculty of Medicine Regenerative and Restorative Medicine Research Center, Istanbul/Turkey

Aim: In this study, it was targetted to evaluate anticancer and apoptotic effects of novel $\beta$-hydroxy ketones on glioblastoma U87 brain cancer cells.

Method: Cell viability analysis were performed as described in CellTiter-Glo® Luminescent Cell Viability Assay kit. Appropriate Inhibitor Concentrations (IC50) of molecules were calculated by using GraphPad Prism 7 software. In logarithmic phase of growth, U87 cancer cells were treated with minimum effective (IC50 doses) doses of molecules for $36 \mathrm{~h}$. For apoptosis detection, DNA fragmentation analysis was used. Western blot analysis was carried out for the detection of Voltage-dependent anion channels (VDAC) protein expression. Control cells were treated with $0.1 \%$ DMSO. The values of $p<0.05$ were taken to be statistically significant.

Findings: According to CellTiter-Glo ${ }^{\circledR}$ Luminescent Cell Viability Assay, IC50 values was obtained for compound $3 \mathrm{~h}, 3 \mathrm{i}, 3 \mathrm{j}, 3 \mathrm{k}, 31,3 \mathrm{~m}, 3 \mathrm{n}$ and $3 \mathrm{o}$ and determined as 3,6; 3,6; 7,$4 ; 3,1 ; 6,6 ; 134,6 ; 333,5$ and $107,3 \mu \mathrm{M}$, for U87 cells respectively. After cells treated with these molecules for $36 \mathrm{~h}$, DNA fragmentation analysis was carried out and smearing DNA was obtained in compound 31. Compound 31 was thought as the most potential compound against U87 brain cancer cells. So, after cancer cells were treated with compound 31, expression of VDAC protein was detected by western blot analysis and increased after cancer cells treated with 31 compound.

Results: The most apoptotic DNA smearing image was seen in compound 31, when compared with control. Apoptotic U937 cells was used as positive control. Increase of VDAC expression can be related to $\mathrm{Ca} 2+$ transfer to the outer mitochondrial membrane inside the cytosol due to the apoptosis mechanism initiation.

Keywords: cancer cells, protein, DNA

\section{OP-23}

INVESTIGATION OF COMBINED THERAPY OF TRASTUZUMAB AND LONIDAMINE ON HER2 POSITIVE BREAST CANCER

Fatma Özlem Zurnac1 ${ }^{1}$, Şükran Özdatlı Kurtuluş², Mustafa Güzel $^{1}$

${ }^{1}$ Istanbul Medipol University, Research Institute for Health Sciences and Technologies (SABITA), Center of Drug Discovery and Development, Department of Molecular Medicine and Biotechnology, Istanbul, Turkey

${ }^{2}$ University of Health Sciences, Hamidiye Faculty of Pharmacy, Department of Pharmaceutical Occupational Sciences, Department of Pharmaceutical Toxicology, Istanbul, Turkey

Aim: The main purpose of the presentation is to develop a combined drug therapy that can be used in HER2positive breast cancer. In our study, we expect to achieve a synergistic effect by targeting HER2 and HK2 pathways. HER2 targeted to prevent proliferation and HK2 targeted to inhibit glycolysis pathway on cancer cells. Inhibition of the HER2 pathway was achieved with trastuzumab and glycolysis inhibition was achieved with lonidamine, an HK2 inhibitor.

Methods: To achieve these purposes, Cell viability analysis was performed with the CellTiter-Glo Luminescent Cell Viability Assay. Apoptosis was analyzed by the Annexin V-PI assay. Scratch assay was performed for the analysis of cell migration. In addition, the protein expression level was determined by Western Blot analysis.

Results: According to cell viability analysis, lonidamine and trastuzumab IC50 value was determined as $125 \mu \mathrm{M}$ and $10 \mu \mathrm{g} / \mathrm{ml}$ as respectively. Experiments were then performed with cells exposed to the drug for 48 hours. Late apoptosis increased significantly in the LND+Tmab combination group compared to the control and drugs alone groups. In addition, 
according to the scratch assay experiment, a significant wound area was obtained in the LND+Tmab combination group. According to western blot analysis, significant HK2 inhibition was determined in the same combination group.

Conclusion: Reduction of cell survival and induced apoptosis are expected due to the combined inhibition of the HER2 receptor and HK2 enzyme. The combination of LND+Tmab produced synergistic effects. In our study, we present the molecular mechanisms demonstrating that the combination of Trastuzumab and Lonidamine and it was thought that it can be an effective treatment in HER2positive breast cancer.

Keywords: Glycolysis, Trastuzumab, Lonidamine, HER2, HK2

\section{OP-24}

SELENIUM DIMINISHES THE EFFECT OF 2100 MHZ MOBILE PHONE IN CELL VIABILITY AND CYCLIN D1 ACTIVITY IN C3H CANCER FIBROBLAST CELLS

\section{Dilek Duzgun Ergun}

Department of Biophysics, Faculty of Medicine, Istanbul Aydin University, Istanbul, Turkey

Aim: In recent studies with cell culture, animal models and biological samples, it has been reported that electromagnetic fields (EMF) emitted by mobile phones may have excitatory or inhibitory effects on cell proliferation, cell division, apoptosis and oxidative stress. It is known that cyclin D1 activity is associated with cell proliferation and the risk of carcinogenesis by taking part a key role in the control of the cell cycle. Micronutrient supplements are recommended in cancer treatment as anticancer and antitoxic agents. Selenium (Se) is an essential micronutrient that has been frequently investigated in recent years due to its anticancer activity.

Material-Methods: In the current study, cells were divided into four groups as control, sham control, $2100 \mathrm{MHz}$ EMF, and $200 \mathrm{nM} \mathrm{Se}+2100 \mathrm{MHz}$ EMF. Cell viability and cyclin D1 activity were measured for each group.

Results and Conclusion: It was determined that exposure to mobile phone EMF for $2 \mathrm{~h}$ in $\mathrm{C} 3 \mathrm{H}$ cancer fibroblast cells increased cell viability $(\mathrm{p}<0.05)$ and cyclin D1 activity $(\mathrm{p}<0.01)$, whereas cell viability $(\mathrm{p}<0.01)$ and cyclin D1 activity $(\mathrm{p}<0.001)$ decreased $200 \mathrm{nM} \mathrm{Se}+2100 \mathrm{MHz}$ EMF group. Our findings suggest that $2100 \mathrm{MHz}$ mobile phone EMF causes enhancement in cell viability and cyclin $\mathrm{D} 1$ activity in $\mathrm{C} 3 \mathrm{H}$ cancer fibroblast cells and selenium supplementation can be considered as a protective agent against the damage of mobile phone EMF.

Keywords: Cell viability, C3H cancer cells, Cyclin D1 activity, $2100 \mathrm{MHz}$, Selenium

\section{OP-25}

CAULERPIN FROM CAULERPA CYLINDRACEA INHIBITS CELL PROLIFERATION, MIGRATION AND INVASION IN HCT-116 HUMAN COLORECTAL CANCER CELL LINE

Nazli Mert Ozupek ${ }^{1}$, Levent Cavas², Hatice Nur Olgun², Hulya Ellidokuz ${ }^{4}$, Yasemin Basbinar ${ }^{5}$

${ }^{1}$ Department of Basic Oncology, Institute of Health Sciences, Dokuz Eylul University, Izmir, Turkey

${ }^{2}$ Department of Chemistry, Faculty of Sciences, Dokuz Eylul University, Izmir

${ }^{3}$ Department of Pediatric Oncology, Institute of Oncology, Dokuz Eylul University, Izmir, Turkey

${ }^{4}$ Department of Preventive Oncology, Institute of Oncology, Dokuz Eylul University, Izmir, Turkey

${ }^{5}$ Department of Translational Oncology, Institute of Oncology, Dokuz Eylul University, Izmir, Turkey

Introduction-Aim: Caulerpa cylindracea, invasive green macroalgae, secretes different bioactive secondary metabolites. Caulerpin is one of the metabolites from $\mathrm{C}$. cylindracea and it has been used for cancer studies. The aim of this study is to evaluate anti-proliferative, antiinvasive and anti-migrative effects of caulerpin from an invasive species, C. cylindracea, on HCT-116 colorectal cancer $(\mathrm{CRC})$ cell line.

Materials-Method: C. cylindracea samples were collected from Dikili-Turkey. Caulerpin was isolated from the samples by using soxhlet extraction and characterized with MALDI-TOF/MS. The anti-proliferative activity of 60-160 $\mu \mathrm{M}$ caulerpin was tested on HCT-116 cell line. The viability of the HCT-116 cells was tested with WST1 reagent at 450/630 $\mathrm{nm}$. The anti-invasive and antimigrative activities of caulerpin on HCT-116 cell line were evaluated via xCELLigence RTCA DP system and wound healing assay, respectively.

Results: The MALDI-TOF/MS result reveals that the peak at $398 \mathrm{~m} / \mathrm{z}$ was caulerpin. IC50 and IC10 values of caulerpin for HCT-116 cell line were calculated as 119 $\mu \mathrm{M}$ and $73 \mu \mathrm{M}$, respectively. Wound healing assay results reveal that after $48 \mathrm{~h}$ of incubation, the control group and $73 \mu \mathrm{M}$ caulerpin exhibited $40.6 \%$ and $6.8 \%$ closure, respectively. The results of xCELLigence RTCA DP show that the rate of HCT-116 cell invasion through matrigel was decreased in cells following 48 hours of treatment with 73 $\mu \mathrm{M}$ caulerpin as compared with control cells.

Discussion-Conclusion: In this study, anti-proliferation, anti-invasion and anti-migration activities of caulerpin against HCT-116 cell line were carried out. The results reveal that caulerpin from $\mathrm{C}$. cylindracea inhibits cell proliferation, migration and invasion in HCT-116 CRC cell line, thus caulerpin could be a promising agent from natural source. 
Further studies are strongly recommended to clarify the effect mechanism of caulerpin against CRC. (This study was funded by Dokuz Eylul University Scientific Research Projects (Grant number:2018.KB.SAG.079) and NMO is supported by CoHE 100/2000 and TÜBİTAK 2211/A Scholarship Project).

Keywords: caulerpin, colorectal cancer, invasive species, natural product

\section{OP-26 \\ COMBINED THERAPY OF CAPECITABINE AND MOCETINOSTAT INDUCE p53/ CASPASE- MEDIATED APOPTOSIS IN 4T1 BREAST CANCER CELL LINE}

\section{Hacer Kaya Çakır, Onur Eroğlu}

Department of Molecular Biology and Genetics, Bilecik Seyh Edebali University, Bilecik, Turkey.

Aim: Combined therapy is emerging as an important with reduced side effects, maximum therapeutic effect. Mocetinostat is HDAC inhibitor and mechanism has yet to be defined. Capecitabine is an anti-cancer chemotherapy drug. The aim of this study is to compare and evaluate the effects of single administration of capecitabine and mocetinostat and their combined application at low doses on the 4T1 breast cancer cell line

Methods: Cell viability was determined by MTT assay for $48 \mathrm{~h}$ and the dosage range of Capecitabine was 100$2000 \mu \mathrm{M}$ and Mocetinostat was $1,675-25 \mu \mathrm{M}$. To determine cytotoxic effect of drugs a combination was used for survival assay for $24 \mathrm{~h}, 48 \mathrm{~h}$ and $72 \mathrm{~h}$. DNA fragmentation assay was performed to confirm cell death via apoptosis. Caspase 3, 7, 9, Bax, Bcl-2, p53 protein levels were determined by western blot analysis.

Findings: We observered the concentration of a drugs that gives half-maximal response(IC50) $1700 \mu \mathrm{M}$ for Capecitabine, $3,125 \mu \mathrm{M}$ for Mocetinostat and $50 \mu \mathrm{M}$ Capecitabine+1,5 $\mu \mathrm{M}$ Mocetinostat for combine treatment. Combine therapy was shown decrease $(69 \%)$ in viable cells at $48 \mathrm{~h}$. We observed that cell proliferation decreased, DNA fragmentation increased compared to control grup. p53,cas3, cas $9 \uparrow$ protein levels increased while cas 7,Bcl-2, Bax protein levels decreased which involved in the apoptotic pathway.

Results: The fact that Capecitabine and Mocetinostat will increase the anticancer activity of drugs when applied for the first time. Combined therapy induced programmed cell death in the 4T1 cells were mediated with the elevated expression of p53 and apoptotic markers such as caspase-7, caspase-9, caspase-3, Bax, Bcl-2 These observations established that Capecitabine and Mocetinostat provoked p53/caspase-mediated programmed cell death. These results show that combined theraphy is more effective than monotherapy. Cancer cells may less to have resistance to multiple drugs treatment and this approach increases the chance of effective treatment.

Keywords: Apoptosis, Breast Cancer, Capecitabine, Combined Therapy, 4T1, Mocetinostat

\section{OP-27 \\ ACANDIDATE NOVEL METHOD FOR INHIBITION OF THE HEDGEHOG SIGNALING PATHWAY: COMBINATION TREATMENT}

\section{Aslıhan Karadağ ${ }^{1}$, Yasemin Başbınar ${ }^{2}$}

${ }^{1}$ Department of Translational Oncology, Institute of Health Sciences, Dokuz Eylul University, Izmir, Turkey

${ }^{2}$ Department of Translational Oncology, Institute of Oncology, Dokuz Eylul University, Izmir, Turkey

Aim: Cancer is the disease with the highest mortality and incidence worldwide. Intercellular and intracellular signaling pathways have an effect on cancer evolution. Abnormal Sonic Hedgehog signaling(Shh) activation in adulthood has been shown to play an important role in the processes of neoplastic growth, evolution of cancer stem cells, and metastasis. In the absence of the Shh, the 12-transmembrane protein Patched(Ptch) acts catalytically to inhibit the activity of the 7-transmembrane protein Smoothened(Smo). Hedgehog signaling pathway(Hh) activation causes changes in primary cilia in the cell membrane. After Ptch removes the inhibition on Smo, Smo is sequentially phosphorylated by cytoplasm proteins. Then, the Glioma-associated oncogene 1(Gli1) transcription factor, which is in its active form, is translocated to the cell nucleus and the target genes are transcribed. In this study, it was aimed to reduce the proliferative and invasive characteristics of cancer cells by inhibiting $\mathrm{Hh}$.

Method: For this purpose, the presence of $\mathrm{Hh}$ was demonstrated in the glioblastoma cell line U87-MG and the combined use of Ptch antagonist Robotnikinin and Smo inhibitor Vismodegib on Hedgehog signaling was investigated. Combination treatment were performed with selected doses after treatment of cells with robotnikin and vismodegib alone. In order to observe this effect, cell proliferation, migration and invasion analyzes were performed.

Results: The results obtained from in vitro studies show that effective results can be obtained with combined treatment. It has been observed that the combined use of agents in combined treatments is more effective than their use alone.

Discussion: Clarifying the signaling pathways will increase the knowledge about cancer and can be a guide in the diagnosis and treatment of cancer. This study shows that inhibition of the $\mathrm{Hh}$ with specific inhibitors and antagonists can be considered as an innovative way of cancer therapy. 
This work was supported by Dokuz Eylul University Scientific Research Coordination Unit (Project Number:2020.KB.SAG.021).

Keywords: Combination treatment, Hedgehog signaling pathway, Robotnikinin, Vismodegib

\section{OP-28}

EFFECTS OFN-MYC DOWNSTREAMREGULATED GENE-2 ON METASTATIC CELL BEHAVIOR OF FTC-133 HUMAN FOLLICULAR THYROID CARCINOMA CELLS

$\underline{\text { Murat Sipahi }}^{1}$, Didem Keleş Bartık ${ }^{2}$, Seniz Inanc ${ }^{1}$, Hande Efe $^{3}$, Zeynep Yüce ${ }^{4}$, Gülgün Oktay ${ }^{5}$

${ }^{1}$ Department of Biochemistry, Institue of Health Sciences, Dokuz Eylul University, İzmir

${ }^{2}$ Medical Laboratory Techniques, Vocational School of Health Services, Izmir Economy University, İzmir

${ }^{3}$ Department of Medical Biology, Institue of Health Sciences, Dokuz Eylul University, İzmir

${ }^{4}$ Department of Medical Biology, Basic Medical Sciences, Faculty of Medicine, Dokuz Eylul University, Izmir

${ }^{5}$ Department of Medical Biochemistry, Basic Medical Sciences, Faculty of Medicine, Dokuz Eylul University, Izmir

Aim: Metastasis is a complex process, which involves the movement or spread of tumor cells from one tissue or organ to another. Since metastasis is responsible for about $90 \%$ of cancer related deaths, developing new approaches which focus on prevention or reduction of metastasis is very critical. NDRG2 (N-myc downstream regulated gene-2), the second member of $\mathrm{N}$-myc downstream regulated gene family, is a well known tumor suppressor gene in regulating the proliferation, differentiation, apoptosis and metastasis of multiple cancer types. In this study, we investigated the possible effects of expression on metastatic cell behavior of FTC-133 human follicular thyroid carcinoma cells.

Method: FTC-133 cells were transiently transfected with an NDRG2 expression vector (NDRG2-pCMV6-AC-GFP) and a control vector (pCMV6-AC-GFP) for 48 hours. Transfection was validated with Real Time PCR (RTPCR) and western blotting. Matrigel invasion, transwell migration, wound healing (scratch assay), and adhesion assays were performed to evaluate the effect of NDRG2 expression on metastatic cell behavior of FTC-133 cells.

Results: There was no significant alteration in invasive and migratory abilities of NDRG2 overexpressed FTC-133 cells compared to control vector expressing counterparts. However, NDRG2 overexpression significantly decreased lateral migration of FTC-133 cells by $20 \%$. Additionally, a significant reduction was observed in adhesive capability of NDRG2 overexpressing FTC-133 cells.

Conclusion: We conclude that the data we obtained would contribute to the development of new approaches inducing NDGR2 expression in order to prevent or reduce metastatic spread in thyroid cancer. Further investigation is required to elucidate the mechanism underlying the effects of NDRG2 on metastatic cell behavior in thyroid cancer.

Keywords: thyroid cancer, N-myc downstream regulated gene-2, metastatic cell behaviour.

\section{OP-29 \\ THE EFFECT OF CYANIDIN-3-O-GLUCOSIDE ON OXALIPLATIN RESISTANT COLORECTAL CANCER CELLS}

$\underline{\text { Hasan Kurter }}^{1}$, Gizem Calıbasi Kocal ${ }^{2}$, Feriha Toksoz ${ }^{3}$, Yasemin Basbinar ${ }^{2}$, Hulya Ellidokuz ${ }^{4}$

${ }^{1}$ Dokuz Eylul University, Institute of Health Sciences, Department of Translational Oncology, Izmir-Turkey ${ }^{2}$ Dokuz Eylul University, Institute of Oncology, Department of Translational Oncology, Izmir-Turkey

${ }^{3}$ Dokuz Eylul Technology Development Zone, Tailor of Science Innovation Biotechnology Inc, Izmir, Turkey ${ }^{4}$ Dokuz Eylul University, Institute of Oncology, Department of Preventive Oncology, Izmir, Turkey

Aim: Oxaliplatin (OXA), a platinum-based chemotherapeutic drug, is mainly used for colorectal cancer (CRC). However, various factors contribute to chemoresistance such as epithelial-mesenchymal transition (EMT). Thus, new strategies must be developed for CRC. The aim of this study, determination of metastatic character which causes OXA-resistance on the HCT-116 and overcome this acquired resistance by cyanidin-3-Oglucoside $(\mathrm{C} 3 \mathrm{G}) . \mathrm{C} 3 \mathrm{G}$ is in the flavonoid group, which gives plants their red color and is a secondary metabolite of plants.

Methods: OXA-resistant colorectal cells were created by using continuous OXA treatment on HCT-116 (HCT116-ROx). WST-1, wound healing, immunofluorescence staining, and qRT-PCR experiments were performed to characterize HCT-116-ROx. Besides, C3G treatment was used on OXA-resistant colorectal cells (HCT-116$\mathrm{ROx}+\mathrm{C} 3 \mathrm{G})$ for reversing EMT biomarkers on HCT-116$\mathrm{ROx}$.

Results: IC50 values of OXA in the HCT-116 and HCT116-ROx were found to be 52 and $96 \mu \mathrm{M}$, respectively and OXA was treated for $48 \mathrm{~h}$ with cells. Migration rate of HCT-116-ROx increased when compared with the HCT116. However, $\mathrm{C} 3 \mathrm{G}$ reduced the migration rate of HCT116-ROx resistant cells. E-cadherin mRNA expression in HCT-116-ROx was reduced by 0.73 -fold when compared with HCT-116. E-cadherin mRNA expression in HCT116-ROx $+\mathrm{C} 3 \mathrm{G}$ was found to be increased 1.38-fold when compared to HCT-116-ROx. Vimentin mRNA expression in HCT-116-ROx was found to be 1.5-fold increase compared to HCT-116. Vimentin mRNA expression in 
$3^{\text {rd }}$ International Cancer and Ion Channels Congress 2021

HCT-116-ROx + C3G was found to be 0.57 -fold decreased compared with HCT-116-ROx. Although immunofluorescence analyses showed that vimentin and $\mathrm{N}$-cadherin expression increased in the HCT-116-ROx compare with the HCT-116, vimentin and $\mathrm{N}$-cadherin expression decreased in the HCT-116- $\mathrm{ROx}+\mathrm{C} 3 \mathrm{G}$ compare with the HCT-116-ROx.

Discussion: These results suggest that EMT plays a key role on OXA-resistance in colorectal cancer. $\mathrm{C} 3 \mathrm{G}$ inhibits the migration of resistant cell and reverses EMT. Thus, C3G can overcome OXA-resistance caused by metastatic character. (This study was supported by Dokuz Eylul University, Scientific Research Projects 2020.KB.SAG.039.)

Keywords: Cyanidin-3-O-glucoside, colorectal cancer, drug resistance, epithelial-mesenchymal transition

\section{OP-30 \\ A NOVEL MOLECULE FOR LUNG CANCER TREATMENT: CURCUMIN-QUINONE DERIVATIVE}

Funda Özkök ${ }^{1}$, Ebru Hacıosmanoğlu ${ }^{2}$, Yasemin Oyac1 ${ }^{3}$, Başak Varol$^{4}$, Nihal Onul ${ }^{1}$, Sacide Pehlivan ${ }^{3}$

${ }^{1}$ Istanbul University-Cerrahpaşa, Faculty of Engineering, Organic Chemistry, Istanbul-Turkey

${ }^{2}$ Bezm-i Alem University, Faculty of Medicine, Biophysics, Istanbul, Turkey

${ }^{3}$ Istanbul University, Istanbul Faculty of Medicine, Medical Biology, Istanbul, Turkey

${ }^{4}$ Istanbul University, Istanbul Faculty of Medicine, Biophysics, Istanbul, Turkey

Introduction: Curcumin molecule, which is the active component of turmeric spice, is one of the most important members of Chinese traditional medicine for centuries. Curcumin which is isolated from Curcuma Longa has different pharmacological effects such as antimicrobial, antifungal, antioxidant, anti-inflammatory, antitumor, anti-HIV, anti-Alzheimer's, anti-diabetic. It can suppress tumor initiation, progression and metastasis. Lung cancer, which causes the death of 1.8 million people every year, is one of the most important cancer types that threaten human life. Curcumin has been reported to affect different molecular pathways such as vascular endothelial growth factors, nuclear factor $-\kappa \mathrm{B}(\mathrm{NF}-\kappa \mathrm{B})$, mammalian target of rapamycin, PI3/Akt, microRNAs and long non-coding RNAs in the treatment of lung cancer. DNA methylation is the reaction of covalent attachment of a methyl group from the 5-carbon of cytosine to the structure of a $\mathrm{CpG}$ dinucleotide, which plays a role in the carcinogenic process, and alters cell functions by altering gene expression. The presence of hypomethylation in lung cancer cells has been reported in the literature.
Aim: In this study, we aimed to investigate the effects of curcumin-benzoquinone derivative which is synthesized by our group/ applied for patent (Patent No: 2020/22499) and previously determined to have anti-proliferative effects on breast cancer cell lines (MDA-MB-231 and MCF7) on A549 lung cancer cell line.

Method: Curcumin-benzoquinone derivative (1,5 and $10 \mu \mathrm{g} / \mathrm{ml}$ ) was performed to both the A549 lung cancer and the HUVEC cell line that we used as a control, and 3-(4,5-Dimethylthiazol-2-yl)-2,5 -Diphenyltetrazolium Bromide (MTT) and global DNA methylation analyzes by ELISA were performed. Concentrations was determined as a results of MTT assay.

Findings: It was observed that cell proliferation was significantly reduced in A549 cell lines treated with curcumin-benzoquinone derivative molecule compared to the control group. In addition, a percentage increase was observed in the global methylation analyzes. While the percent methylation was 1.625 in the control A549 cell line where the synthesized molecule was not applied, the percent methylation values were found to be 1.741 , 2.812 and 1.946 in the cell lines treated with 1.5 and 10 $\mu \mathrm{g} / \mathrm{ml}$ curcumin-benzoquinone derivative, respectively.

Result: As a result, the newly synthesized curcuminbenzoquinone derivative molecule has an antiproliferative effect by reducing hypomethylation in the A549 lung cancer cell line, suggesting that it may be a drug candidate molecule for the treatment of lung cancer.

Keywords: Curcumin, benzoquinone, A549 lung cancer, antitumor activity, MTT, Global methylation.

\section{OP-31}

\section{CYTOTOXICITY ASSESSMENT OF D-ERYTHRO- MAPP AND NANOPARTICLE FORMULATION IN BREAST CANCER CELLS}

Hüseyin İzgördü, Canan Vejselova Sezer, Hatice Mehtap Kutlu

Eskişehir Teknik Üniversitesi

Objective: Breast cancer is a type of cancer that occurs in both men and women and has a high mortality rate. Cancer researches of recent years are based on sphingolipid metabolism. The key molecule for cancer treatment is ceramide. Ceramides mediate antiproliferative responses such as suppressing cell growth, triggering apoptosis and regulating senescence. Depending on the level of ceramide in the cells, the cells are directed to death or survival can be sustained. Ceramidase enzymes are enzymes that break down the intracellular ceramide, lower the ceramide level in the cells and cause the cells to escape from death. Suppression of these enzymes as new targets for cancer therapy is shown in the literature. 
D - erythro-M A P P ( 1 S , 2 R ) - D - e rythro- 2 - ( N Myristoylamino)-1-phenyl-1-propanol) is an acid ceramidase inhibitor shown to promote apoptosis in cancer cells. In this study, the cytotoxic, antiproliferative, migration inhibitory effects of D-erythro-MAPP and the nanoparticle formulation synthesized by hot homogenization were investigated together with the drug release kinetics of the agents.

Methods: The nanoparticle formulation of D-e-MAPP was synthesized by hot homogenization technique. The cytotoxicity of D-erythro-MAPP and nanoparticle formulation on MCF-7 cells was investigated by MTT (3- (4,5-Dimethylthiazol-2-yl) -2,5-Diphenyltetrazolium Bromide) colorimetric test. The effect of D-erythro-MAPP on MCF-7 cells was investigated by wound healing and colony formation assays. In addition, the drug release kinetics of D-erythro-MAPP were demonstrated by the release assay. Migration assay was performed to detect the migration abilities of the cells.

Results: From the MTT test results, the IC50 concentrations of D-erythro-MAPP and nanoparticle formulation killing half of MCF-7 cells were determined to be 4.4 and 15.6 $\mu \mathrm{M}$, respectively for application of 24 hours. D-erythroMAPP inhibited migration to the scratched area compared to control in the wound healing experiment. In the colony formation assay, it is seen that their application inhibits colony formation. As a result of migration assay, the migration abilities of the cells given D-erythro-MAPP and nanoparticle formulation decreased compared to the control groups. Drug release kinetics underlined that the release of D-erythro-MAPP from the nanoparticle formulation was detected to be controlled resealse in an increased concentration by time-dependent manner.

Conclusion: According to the findings, it was determined that D-erythro-MAPP and nanoparticle formulation have anti-proliferative, cytotoxic and migration inhibitory effects on breast cancer (MCF-7) cells.

This study was supported by The Scientific and Technological Research Council of Turkey (TÜBİTAK).

Keywords: Cancer, MCF-7, Sphingolipid, D-erythroMAPP

\section{OP-32}

\section{A COMPUTATIONAL STUDY OF 17 MECHANOSENSITIVE ION-CHANNELS ON CARCINOGENESIS AND METASTASIS}

Caner Karaca $^{1}$, Asım Leblebici ${ }^{1}$, Yasemin Başbınar ${ }^{2}$ ${ }^{1}$ Dokuz Eylul University, Institute of Health Sciences, Department of Translational Oncology, Izmir, Turkey ${ }^{2}$ Dokuz Eylul University, Institute of Oncology, Department of Translational Oncology, Izmir, Turkey
Objectives: Researchers investigate more physiologically relevant models to mimic the parameters on cancer behavior and therapy. One such parameter, interstitial pressure, is a well-known character of most cancers. An increasing number of studies indicate that mechanical forces modulate cancer behavior on progression, survival, and metastasis. These features promise new therapeutic targets in combination therapies. Yet, the mechanical forces have come to prominence recently despite their renown as cancer hallmark. This computational study focuses on mechanosensitive ion channels to unveil how cancer cells evolve to respond to mechanical forces in colorectal cancer (COAD).

Methods: In order to investigate their role, 17 ion channels based on "mechanosensitive ion channel" molecular function are included in the study. Afterward, mRNA expressions of relevant genes are analyzed according to Genomics Data Commons (GDC) Data Portal of The Cancer Genome Atlas (TCGA). The data is compared among 478 cases with different stages and 41 healthy tissues. (Total sample size is 519)

Results: The results illuminate that 10 of 17 mechanosensitive ion channels are involved in carcinogenesis. PIEZO2, TMC4, CSCL2, TMC8, and T150C are downregulated, whereas TMC6, PIEZ01, CSCL1, and TRPV4 are upregulated in the stage 1 COAD group according to healthy tissues. Moreover, TMC7, TRPV4, FAM155A are also related to metastasis since their expressions are increased in stage 4 according to stage 2 in colorectal cancer.

Conclusion: Mechanosensitive ion channels dawn as potential targets to manage cancer progression and metastasis. More comprehensive studies such as miRNA and mutation profiling could support the results and couple metabolic processes with the function of mechanosensitive channels. (A.L. and C.K. are supported within the scope of CoHE 100/2000 and TÜBİTAK 2211/A PhD Scholarships Project and the study is funded by Dokuz Eylul University Scientific Research Projects Coordination Unit with project number 2020.KB.SAG.043.)

Keywords: cancer, carcinogenesis, intersititial pressure, ion channel, metastasis.

OP-33

THE ROLE OF TRPC1 ON EARLY-ONSET ALZHEIMER'S DISEASE

Mine Kocabıyık, Damla Getboğa, Yasemin Eraç Department of Pharmacology, Ege University, Izmir, Turkey

Aim: The purpose of our study was to examine the role of transient receptor potential canonical 1 (TRPC1) which is a component of store-operated calcium entry 
$3^{\text {rd }}$ International Cancer and Ion Channels Congress 2021

(SOCE) and related with Alzheimer's Disease (AD) on the early-onset AD (EOAD) in terms of SOCE and expression levels of SOCE components in SH-SY5Y human neuroblastoma cell line.

Methods: SH-SY5Y cells were transfected with presenilin 1 (PSEN1) plazmid which has the EOAD related point mutation to mimic the disease. TRPC1 overexpression vector was also transfected to investigate the role of TRPC1 on EOAD. Expression levels of SOCE components which are STIM1 and Orai1 were measured with quantitative realtime RT-PCR. Changes in SOCE were monitored in fura-2/ AM loaded cells with sarcoplasmic/endoplasmic reticulum Ca2+ ATPase (SERCA) blocker cyclopiazonic acid (CPA).

Results: Point mutation that is related with EOAD at PSEN1 gene caused the decrease in CPA-induced SOCE significantly compared to empty vector transfected control cells. When TRPC1 over-expressed PSEN1 mutant cells were compared with TRPC1 over-expressed SH-SY5Y cells in terms of SOCE, a statistically significant decrease was observed. According to our quantitative real-time RTPCR results, STIM1 expression increased while Orail expression decreased in mutant PSEN1 cells. On the other hands, STIM1 expression levels decrease while Orai1 expression levels increase insignificantly in TRPC1 overexpressed PSEN1 mutant cells.

Conclusion: According to our results, decrease of SOCE in PSEN1 mutant cells is related with attenuated Orail mRNA expression levels. In addition, over-expression of TRPC1 in PSEN1 mutant cells caused to increase in Orail expression levels whereas to decrease in STIM1 expression levels. TRPC1 may play a regulatory role in SOCE, Orai1 and STIM1 expression levels. In conclusion, TRPC1 and SOCE may be a therapeutical target for EOAD.

Keywords: Alzheimer's Disease, Ion channel, Storeoperated calcium entry, TRPC1

\section{OP-34}

\section{IN SILICO STUDY OF GENE EXPRESSION DIFFERENCES OF VOLTAGE GATED SODIUM CHANNELS IN BREAST CANCER}

Ezgi Daskin $^{1}$, Asim Leblebici ${ }^{1}$, Yasemin Basbinar ${ }^{2}$ ${ }^{1}$ Department of Translational Oncology, Institute of Health Sciences, Dokuz Eylul University, Izmir, Turkey

${ }^{2}$ Department of Translational Oncology, Institute of Health Sciences, Dokuz Eylul University, Izmir, Turkey; Department of Translational Oncology, Institute of Oncology, Dokuz Eylul University, Izmir, Turkey

Aim: Breast cancer is a lethal disease that is affected by various types of pathways. The aggressiveness of breast cancer is dependent on the presence of hormone receptors, ion channels, and growth factors. Voltage-gated sodium channels (VGSC) are generally expressed in excitable cells such as muscle cells and neurons. Voltage-gated sodium channels are abnormally expressed in breast cancers and play a crucial role in cancer aggressiveness via increase of proliferation and metastasis. Voltage-gated sodium channels have nine alpha and two beta subunits, and the presence of the subunits varies in each cell type. In this study, we aimed to demonstrate the relationship between gene expression levels of alpha and beta subunits of VGSC and breast cancer via in silico study.

Method: 130 normal and 1091 breast cancer tissue data were collected from The Cancer Genome Atlas-Breast Cancer (TCGA-BRCA) project database. There were 13 different gene expressions of alpha and beta subunits of VGSC. Normalization and filtration were applied on the data and fold-change of both tissue samples were calculated. To detect the differential expression of those genes, fdr $\mathrm{p}$-value was chosen as $<0.05$ and fold-change cut off was chosen as $>=|1|$.

Results: As a result, the increase of gene expression in primary tissue compared to normal tissue had significant results in 5 of 13 genes. Surprisingly, Nav1.1 alpha-subunit gene, SCN1A, gene expression has dramatically increased on primer tissues compared to normal tissue than other VGSC genes with 5.17 fold change. SCN4A and SCN2B gene expression levels were decreased compared to normal tissue levels.

Conclusion: In conclusion, some alpha and beta subunits' gene expression levels of VGSCs are parallel in literature and some of them were opposite of the literature. Although Nav1.5 alpha subunit was proved to express the most in breast cancer in vitro studies in literature, SC5A gene expression level had no significant results on breast cancer according to our results. Further in vitro studies are required to prove the effect of alpha and beta subunits on breast cancer aggressiveness.

Keywords: Breast cancer, Cancer aggressiveness, Gene expression, TCGA, Voltage-gated sodium channels

OP-35

THE EFFECT OF HISTONE DEACETYLASE INHIBITORS AND AUTOPHAGY MODULATION ON CARCINOGENESIS OF CHEMORESISTANT CHOLANGIOCARCINOMA CELLS

\section{Helin Sağır ${ }^{1}$, Emel Başak Gencer Akçok ${ }^{2}$}

${ }^{1}$ Abdullah Gul University, Graduate School of Engineering and Science, Bioengineering Department, Kayseri, Turkey ${ }^{2}$ Abdullah Gul University, Faculty of Life and Natural Sciences, Molecular Biology and Genetics Department, Kayseri, Turkey

Aim: Cholangiocarcinoma (CCA) is an aggressive adenocarcinoma and the second most common primary liver tumor. 
$3^{\text {rd }}$ International Cancer and Ion Channels Congress 2021

Since the current chemotherapeutic treatments are not effective because of the multidrug resistance, chemoresistant CCA is prevalent. The histone deacetylase inhibitors (HDACis) have shown promising anticancer properties and dysregulation of HDAC related to pathways in chemoresistance CCA such as PTEN/PI3K/AKT/ mTOR which is important for autophagy. Our aim is to investigate the effect of HDAC inhibition and autophagy manipulation on chemoresistant cells and achieve reversal of the resistance.

Method: We maintained EGI-1 and TFK-1 parental CCA cells and generated cisplatin-resistant EGI-1 and TFK-1 CCA cell lines by implementing increasing concentrations of cisplatin on cells. MTT cell proliferation assay was performed in order to investigate the combinational effect of HDAC inhibition by Romidepsin and autophagy inhibition by Nocodazole. Apoptosis was determined by Annexin V-FITC/PI double-staining and the cells were analyzed by flow cytometry. The effect of the inhibitors on cell cycle distribution was achieved by propidium iodide staining.

Findings: The combinational treatment with IC50 (drug concentration that inhibits cell growth by $50 \%$ ) concentration of inhibitors for 48 hours has decreased the proliferation of cisplatin-resistant cells significantly when compared to untreated control cells. The drug combination decreased the cell proliferation by $85 \%$ and $50 \%$ for EGI- 1 and TFK-1 cells, respectively. The apoptosis assay has been performed and the population of early apoptotic cells was increased upon combination treatment by 17 and $57.4 \%$ in EGI-1 and TFK-1 cells, respectively. Additionally, necrotic cell death did not occur which demonstrated the apoptotic effect of the combination treatment. Also, cell cycle analysis results have shown cell cycle arrest in G0/ G1 phase.

Results: Although there is a need for further investigation, our results suggest that the combination therapy against HDAC and autophagy inhibition could be a promising therapeutic approach for chemoresistant cholangiocarcinoma.

Keywords: chemoresistance, cholangiocarcinoma, HDAC inhibitors, autophagy, combination therapy

\section{OP-36 \\ SELF TARGETING OF CANCER CELLS USING CRISPR/CAS9 GENE EDITING SYSTEM}

$\underline{\text { Ozan Topcu }}^{1}$, Nihal Karakaş ${ }^{2}$

${ }^{1}$ Medical Biology and Genetics Program, Institute of Health Sciences, İstanbul Medipol University; Cancer Research Center, Research Institute for Health Sciences and Technologies (SABITA), İstanbul Medipol University ${ }^{2}$ Cancer Research Center, Research Institute for Health Sciences and Technologies (SABITA), İstanbul Medipol
University, Department of Medical Biology, School of Medicine, İstanbul Medipol University

Aim: One of the rising phenomenon in new generation cancer therapies is "hit the cancer with itself" by use of receptor self-targeted cancer cells. Tumor cells exhibit a "self-homing" behavior, whereby cells released into the circulation can home back to the main tumor site. We envision that patients' own cancer cells can be engineered ex vivo with receptor-targeted antitumor agents, and also an inducible suicide system can be integrated before being re-administered by different routes.

Method: In this study, we developed toxin resistant Ln229 (IL13Ra2 receptor negative) GBM cancer cells (Ln229mEF2). We showed that Ln229 GBM cell line is lack of the cognate receptor expression. Subsequently, we introduced a point mutation ( $\mathrm{G}$ to $\mathrm{A}$ transition) on $\mathrm{EF}-2$ sequence which confers to toxin resistance by using CRISPR/Cas9 gene editing system. Then we confirmed the mutation $G$ to A transition by genomic sequencing. Afterwards, we selected toxin resistant cells upon subsequent treatment with purified toxin. Finally, we transfected Ln229-mEF2 cells with IL13PE coding (LV-IL13PE) plasmid and verified IL13PE toxin expression and secretion by dot blot.

Findings:, Our results showed that Ln229-mEF2 cells bear heterozygous G-to A point mutation. Additionally, Ln229-mEF2 cells showed toxin resistance up to $5 \mu \mathrm{g} / \mathrm{ml}$ DT treatment. After transfection with LV-IL13PE plasmid, we detected soluble IL13PE fusion protein in condition medium of Ln229-mEF2-IL13PE cells. We showed Ln229mEF2-IL13PE condition medium causes $\% 55$ cell death in U87 GBM cells (IL13Ra2 receptor positive) compared to untreated control cells.

Results: Overall, our findings contribute a new toxin based strategy to selectively self killing of cancer cells.

Keywords: Cancer, Cas9, CRISPR, genetic engineering, IL13, recombinant toxins.

\section{OP-37}

ANTIPROLIFERATIVE AND APOPTOTIC EFFECTS OF PROTON PUMP INHIBITOR LANSOPRAZOLE ON DU-145 PROSTATE CANCER CELLS

Buminhan Özgültekin ${ }^{1}$, Iskender Sinan Genco ${ }^{2}$, Nezih Hekim $^{1}$

${ }^{1}$ Biruni University, Faculty of Engineering and Natural Sciences, Department of Molecular Biology and Genetics, Istanbul, Turkey

${ }^{2}$ Memorial Sloan Kettering Cancer Center, Department of Pathology, New York, USA

Introduction/Aim: Ion channel blockers are studied to be used in treatment of cancer from various organs, such as breast, prostate and pancreas. 
Their mechanisms include modulating tumor microenvironment and $\mathrm{pH}$ as well as overcoming chemotherapy resistance. They are also shown to slow invasion and metastasis. Lansoprazole is a proton pump inhibitor that blocks V-ATPase and $\mathrm{H}+/ \mathrm{K}+$ ATPase channels on cells. In this study, we aim to discover antiproliferative and apoptotic effects of Lansoprazole on DU-145 castrationresistant prostate cancer cell lines (CRPCCL).

Materials-Methods: A total of six DU-145 CRPCCL groups were prepared (one control group and 5 different doses of Lansoprazole group (10, 25, 50, 100 and 200 $\mu \mathrm{M})$ ). MTT assay and Trypan blue counting for cytotoxicity were performed at 6th, 16th, 24th, 48th and 72nd hours. We specifically analyzed 6th hour after Lansoprazole administration to understand the early effects of the drug. We identified the most effective doses as 10 and $100 \mu \mathrm{M}$ and evaluated Caspase-9 and PARP-1 expression by Western Blotting. Apoptosis was analyzed by Annexin/PI flow cytometry.

Results: The study results showed that Lansoprazole exhibited cytotoxic effects and decreased cell viability on DU-145 CRPCCL on MTT assay and Trpyan blue cell counting. The Caspase-9 and PARP-1 expression at 6th hour were not significantly increased $(p>0.05)$. We did not detect apoptosis by Annexin/PI flow cytometry at 6th hour $(\mathrm{p}>0.05)$. However, the total cell number/event was declined $20 \%$ for $10 \mu \mathrm{M}$ and $21 \%$ for $100 \mu \mathrm{M}$ Lansoprazole at 6 th hour $(\mathrm{p}<0.05)$.

Conclusion: In conclusion, our study suggests that Lansoprazole promotes a nonapoptotic, caspase-independent cell death on DU-145 CRPCCL as well as supresses cell proliferation and growth dynamics at 6 th hour at 10 and 100 $\mu \mathrm{M}$ doses.

Keywords: DU-145, Ion Channels, Lansoprazole, Prostate Cancer

\section{OP-38}

THE AI-BASED COLORECTAL CANCER
SURVIVAL PREDICTION WEB TOOL AS A
CLINICAL DECISION SUPPORT SYSTEM:
SurVCOCA

$\underline{\text { Huseyin Koray Misirlioglu }}{ }^{1}$, Asim Leblebici ${ }^{1}$, Yasemin Basbinar $^{2}$, Hulya Ellidokuz ${ }^{3}$, Gizem Calibasi Kocal ${ }^{2}$ ${ }^{1}$ Department of Translational Oncology, Institute of Health Sciences, Dokuz Eylul University, Izmir, Turkey ${ }^{2}$ Department of Translational Oncology, Institute of Oncology, Dokuz Eylul University, Izmir, Turkey

${ }^{3}$ Department of Preventive Oncology, Institute of Oncology, Dokuz Eylul University, Izmir, Turkey

Purpose: Proper prognosis and survival prediction of cancer patients are crucial for the classification of cases, optimization, and designing treatment strategies. In this study, we created the machine learning-based CDSS (Clinical Decision Support System), SurvCOCA, which is estimates the survival of colorectal cancer patients.

Method: The data of 456 colorectal cancer patients from the "NCI GDC portal TCGA-COAD project" was used. Clinical and genomic data downloaded by using TCGAbiolinks. While clinical data analyzed by Kaplan-Meier survival analysis, genomic data analyzed by gene expression analysis. Risk groups used as class labels. 4 different (Naive Bayes, Support Vector Machine, Random Forest, and C4.5 Decision Tree) machine learning algorithms trained. All prediction models transformed into a web interface CDSS named "SurvCOCA" via Shiny.

Results: Four of twelve clinical parameters (T, N, M, and Tumor Stage), nine genes, and five metabolic pathway parameters from the KEGG Database and MSigDB were significantly associated with survival. According to the performance results of machine learning algorithm models using the selected parameters as inputs, the Random Forest algorithm was the best in predicting survival with an accurate prediction rate of $76.2 \%$. The Naive Bayes algorithm showed the closest performance $(71.1 \%)$, and the Support Vector Machine algorithm showed the lowest performance (54.0\%). When all the genes, pathways, and clinical parameters are used together as input, relatively higher algorithm performance has been achieved compared to the analysis results performed with other input combinations.

Conclusion: Artificial Intelligence-based CDSS models, which focus on survival outcomes in oncology, are essential in providing foresight for physicians and patients about whether it is worth applying the chemotherapy treatment, which might seriously affect the patient's quality of life. In addition, developing and improving the SurvCOCA and similar systems with more data will make diseases more manageable and help make more accurate decisions for patients.

Keywords: Clinical decision support, colon cancer, machine learning, survival analysis

\section{OP-39 \\ OPTIMIZATION OF CELL VIABILITY ASSAY FOR 3D DYNAMIC CULTURE}

Tolga Sever ${ }^{1}$, Aras Emre Canda ${ }^{2}$, Aslihan Karadag ${ }^{1}$, Gizem Calibasi Kocal $^{3}$, Hulya Ellidokuz ${ }^{4}$, Yasemin Basbinar ${ }^{3}$

${ }^{1}$ Department of Translational Oncology, Institute of Health Sciences, Dokuz Eylül University, Izmir, Turkey ${ }^{2}$ Department of Basic Oncology, Institute of Health Sciences, Dokuz Eylül University, Izmir, Turkey

${ }^{3}$ Department of Translational Oncology, Institute of Oncology, Dokuz Eylül University, Izmir, Turkey

${ }^{4}$ Department of Preventive Oncology, Institute of Oncology, Dokuz Eylül University, Izmir, Turkey 
$3^{\text {rd }}$ International Cancer and Ion Channels Congress 2021

Aim: Conventional in vitro cell cultures are limited to show the effectiveness of the anticancer agents. Therefore most of the agents fail in preclinical models and phase trials. On the other hand, in vivo models are highly expensive, timeconsuming, and labor-intensive for drug screening studies. Thus there is a necessity for a standardized novel system. The study aims to standardize a cell viability protocol for an in vitro 3D microfluidic system which could be used for drug screening in the cancer field.

Method: Colorectal cancer cell suspension (includes 1x104 cells), was prepared as different ratios of matrigel spread on the bottom of the microfluidic system for evaluation of their stability under flow. Cell viabilities were measured by using different agents WST-1, and Presto Blue for 30, 60, 90, 120, 180, 300 minutes. Additionally, trypan blue was used for the normalization of Presto Blue measurements.

Results: Although matrigel with a 1:3 ratio showed stability under flow in the bottom of the microfluidic device, 1:5 and 1:10 ratios were removed. Thus the optimization continued with a 1:3 ratio matrigel. Presto Blue and WST-1 reagents showed the highest intensity of RFU and absorbance values respectively at 180 minutes in $3 \mathrm{D}$ microfluidic culture.

Conclusion: The study provides a standardized protocol for cell viability assay for $3 \mathrm{D}$ cell cultures. As a step ahead, the microfluidic system which is desired to produce, could potentially demonstrate the cytotoxic effect of the chemotherapeutic agents to predict the most effective therapy options in terms of individualized treatment in cancer patients. (T.S. is supported by the Council of Higher Education (CoHE, YOK) and Scientific and Technological Research Council of Turkey (TUBITAK) 2211/A Doctoral Scholarship Project). This study was funded by Dokuz Eylul University Scientific Research Projects (Grant number: 2018.KB.SAG.075)

Keywords: 3D Microfluidic Cell Culture, Drug Screening, Viability Assay

\section{OP-40}

\section{SINGLE CENTER EXPERIENCE: ASSOCIATION OF FLT3 MUTATIONS WITH GENDER AND AGE IN AML}

$\underline{\text { Zeynep Doğru }}^{1}$, Akif Ayaz ${ }^{1}$, Fatma Seca Giriş ${ }^{1}$, Mehmet Koçak $^{2}$, Murat Elli ${ }^{3}$, Onur Gökmen Sevindik ${ }^{4}$, Hüseyin Saffet Bekoz ${ }^{4}$, Ali İhsan Gemici ${ }^{4}$, Sevil Sadri ${ }^{4}$, Yöntem Yaman $^{3}$, Türkan Yiğitbaş ${ }^{5}$, Seniye Sema Anak ${ }^{3}$

${ }^{1}$ Istanbul Medipol University, Genetic Diagnosis Center, Turkey

${ }^{2}$ Istanbul Medipol University, Department Of Biostatistics and Medical Informatics, Turkey

${ }^{3}$ Istanbul Medipol University, Department of Pediatric Hematology and Oncology, Turkey

${ }^{4}$ Istanbul Medipol University, Department of Hematology, Turkey
${ }^{5}$ Istanbul Medipol University, Department Of Biochemistry, Turkey

Aim: Acute myeloid leukemia (AML) is a clinically heterogeneous malignancy, which is characterized by clonal expansion of myeloid progenitors in the bone marrow and peripheral blood. The most common genetic changes in AML patients are mutations of the FMS-like tyrosine kinase 3 (FLT3) gene, which is plays an important role in hematopoietic cell survival, proliferation and differentiation. We aim to investigate distribution of FLT3 mutations according to gender and age with our data.

Methods: 141 patients (61 female, 80 male) who applied to our institution between 2016-2021 in order to evaluate the presence of mutation in the FLT3 gene were included in the study. ITD and TKD mutations were evaluated by Fragment analysis. Logistic regression models were constructed using SAS (Version 9.4, Cary, North Carolina, USA) was used for statistical analysis.

Findings: FLT3 (ITD or TKD) mutations were detected positive in $27(19.1 \%)$ of 141 patients. Of these, 24 were ITD and only 3 were TKD mutations. FLT3 positivity was detected in $21(18.3 \%)$ of 115 patients older than 18 years of age. It was detected in $6(23.1 \%)$ of 26 patients younger than 18 years of age. Based on gender-specific data, FLT3 mutation was found in $16(26.2 \%)$ of 61 female patients and it was detected in 11 (13.8\%) of 80 male patients. A bivariable model of age and gender revealed that odds of having FLT3 mutation was at least two times higher in Females compared to Males (OR=2.23, 95\% CI: 0.95, 5.24, $\mathrm{p}=0.066)$ while age was not a significant factor $(\mathrm{p}=0.51)$ with no significant agegender interaction $(\mathrm{p}=0.41)$.

Conclusion: Gender has a suggestive association with the likelihood of FLT3, where females had much higher likelihood of having FLT3 mutation compared to males.

Keywords: Acute myeloid leukemia, FLT3-ITD, FLT3-TKD

OP-41

GENERATION OF R132H POINT MUTATION BY CRISPR/Cas9 METHOD IN COLON CANCER CELL LINE

Esra Bulut Atalay $^{1}{ }^{2}$, Şerif Şentürk ${ }^{1}$, Şerif Şentürk ${ }^{2}$, Hülya Ayar Kayalı ${ }^{1}$, Hülya Ayar Kayalı ${ }^{2}$, Hülya Ayar Kayalı ${ }^{3}$ ${ }^{1}$ Izmir International Biomedicine and Genome Institute, Dokuz Eylül University, Izmir, Turkey

${ }^{2}$ Izmir Biomedicine and Genome Center, Izmir, Turkey ${ }^{3}$ Department of Chemistry, Division of Biochemistry, Faculty of Science, Dokuz Eylul University, İzmir, Turkey

Objective: Isocitrate dehydrogenase (IDH) enzymes role in the decarboxylation of isocitrate to $\alpha$-Ketoglutarate $(\alpha-\mathrm{KG})$ in the TCA cycle. 
$3^{\text {rd }}$ International Cancer and Ion Channels Congress 2021

However, tumor-based point mutations occur in arginine residues (such as R140, R132, R170, etc.) in the active sites of IDH enzymes and mutant IDH enzymes catalyze $2-\mathrm{HG}$ conversion from $\alpha-\mathrm{KG}$. While $2-\mathrm{HG}$ is found in very small amounts in healthy cells, its excessive synthesis and accumulation in cancer cells direct the cell to metastasis. The aim of this project is to create R132H mutation by CRISPR/ Cas9 method in SW620 colon adenocarcinoma cells whose $2 \mathrm{HG}$ level was predetermined.

Material-Methods: First, nocodazole was treated to cells to block them in the $M$ phase and the Cas9 enzyme was used to generate site-specific double-strand DNA breaks. Synchronized cells were given RNP complex to repair the generated DNA breaks by the HDR mechanism. Nucleofection was performed with the SF cell line 4D nucleofector kit. DNA was extracted from 5 single cells with DNeasy Blood \& Tissue Kits and the PCR products were analyzed by Sanger Sequencing.

Results: The nucleofection rate was determined as $86.6 \%$. After nucleofection, cells were seeded in 96 well plates, one cell per well, and 5 single-cell clones were selected. The clone containing the $\mathrm{R} 132 \mathrm{H}$ point mutation was identified both by cutting with the BclI enzyme and by Sanger sequencing. As a result, it was determined that 1 clone contained the target mutation.

Conclusion: Recently, CRISPR/Cas9-based genome editing has been used to create genetic models specifically to study and treat human genetic diseases associated with point mutations. In the current project, $\mathrm{R} 132 \mathrm{H}$ mutation was successfully generated to study the effects of $2 \mathrm{HG}$ in colon cancer metastasis. The used method allows site-specific and high-efficiency point mutation generation and can be used for the creation of new models in the future.

Keywords: CRISPR/Cas9 method, point mutation, colon cancer.

\section{OP-42 \\ IN SILICO DESIGNED NEXT-GENERATION VACCINE AGAINST TRPM4 ION CHANNEL FOR COLORECTAL CANCER IMMUNOTHERAPY}

\author{
$\underline{\text { Ali Șahin }}^{1}$, Huseyn Babayev ${ }^{1}$, Fatıma Hacer Kurtoglu², \\ Husamettin Vatansev ${ }^{3}$ \\ ${ }^{1}$ Selcuk University Faculty of Medicine, Konya, Turkey \\ ${ }^{2}$ Koc University Institute of Health Scinces, Department of \\ Cellular and Molecular Medicine, Istanbul, Turkey \\ ${ }^{3}$ Selcuk University Faculty of Medicine, Department of \\ Biochemistry, Konya, Turkey
}

Aim: Transient receptor potential melastatin-4 channel (TRPM4) dysregulation contributes to heart conditions, immune diseases, colorectal, cervical, and prostate cancer. TRPM4 plays a versatile role in colorectal cancer cell proliferation, cell cycle, and invasion. The overexpression of
TRPM4 is associated with poor prognosis, drug resistance, metastasis, more heterogeneity, and immune evading. The overexpressing of TRPM4 gives it the cancer vaccine target.

Method: Candidate linear T cell epitopes predicted in IEDB, Proteasomal cleavage/TAP transport/MHC class I combined prediction tool. Predicted linear T cell epitopes were selected based on antigenicity, allergenicity, and toxicity. Linear B cell epitopes predictions are performed in several webservers with different algorithms to improve prediction quality. In silico tools assessed antigenicity, allergenicity, and toxicity properties of predicted linear B cell epitopes. Epitopes linked with GPGPG sequence and CEL-1000 fragment added to both head and tail of the construct with EAAAK linkers. The secondary structure of the vaccine sequence was predicted with GOR4 and RaptorX software. The 3D structure of the construct was modeled with the GalaxyTBM server and further refined using the GalaxyRefine2. The refinement process of the tertiary structure was evaluated with ERRAT and ProCheck tools.

Findings: Candidate linear T cell and B cell epitopes were selected according to predicted IC50 values, antigenicity, allergenicity, and toxicity scores. TRPM4 vaccine has no significant sequence similarity with other known human proteins. The designed TRPM4 vaccine is verified as antigenic (0.5575) for targeting overexpressing cancer cells and non-allergenic to P54259. The physicochemical analyses show vaccine construct stable and proper for peptide purification.

Results: Overall, results showed that the potential vaccine against TRPM4 could be a promising agent against colorectal cancer. The approach of this study efficiently minimized the tests, cost, and time required to select the best epitopes and design a vaccine for the treatment of colorectal cancer.

Keywords: Cancer, ion channels, TRPM4, colorectal cancer, cancer vaccine, immunotherapy.

\section{OP-43 \\ EXOSOME-MEDIATED EFFECTS CARCINOGENIC MECHANISMS IN OVARIAN TUMOUR MICROENVIRONMENT CELLS}

Gizem Yılmaz', Zehra Tavşan³, Elçin Cağatay¹, Gizem Kurşunluoğlu² ${ }^{2}$, Hülya Ayar Kayalı ${ }^{4}$

${ }^{1}$ Izmir International Biomedicine and Genome Institute, Dokuz Eylül University, Izmir

${ }^{2}$ Izmir Biomedicine and Genome Center, Izmir

${ }^{3}$ Department of Chemistry, Faculty of Science, Dokuz Eylül University, Izmir

${ }^{4}$ Izmir International Biomedicine and Genome Institute, Dokuz Eylül University, Izmir; Izmir Biomedicine and Genome Center, Izmir; Department of Chemistry, Faculty of Science, Dokuz Eylül University, Izmir 
$3^{\text {rd }}$ International Cancer and Ion Channels Congress 2021

Aim: Ovarian cancer is the fifth most common cause of cancer death in women, although it has a low incidence of $3 \%$ among gynaecological diseases. It is essential to explain the carcinogenesis mechanism of ovarian cancer to overcome the difficulties in diagnosis at the early stage, the poor prognosis at the late stages of the disease, and the low survival rate after surgery and chemotherapy. This mechanism includes the reprogramming of tumour microenvironment in both the primary and secondary regions and the reprogramming is mediated by exosomes released from cancer cells by transferring pro-tumorigenic conditions. The aim of this study is to show the uptake of exosomes by primary cancer cells (A2780), epithelial cells (OSE) which are the basis of ovarian cancer in the primary region and mesothelial (MeT-5A) cells in the secondary region, and investigate the variations in the carcinogenic mechanisms, especially changes in the reactive oxygen species (ROS) levels, proliferation patterns and phosphokinase signaling.

Method: The exosomes were isolated from cisplatin resistant A2780 cells by ultrafiltration and differential centrifugation. Confocal imaging was used to demonstrate the uptake of exosomes released from ovarian cancer cells. ROS analysis was done using DCFH-DA Cellular ROS assay kit. Cell proliferation was calculated by the determination of ATP levels using an ATP bioluminescence assay kit. A2780 and OSE cells were stimulated with exosomes for phosphokinase antibody array and levels of phosphorylated proteins were analyzed.

Results: ROS production has increased in A2780 and OSE cells except for MeT-5A cells. Proliferation were induced in the recipient cells following the exosome uptake. Furthermore, treatment of recipient cells with exosomes resulted in the differentiation of phosphokinase signaling including STAT, Erk, Wnt and AMPK pathways.

Conclusion: In conclusion, the carcinogenesis mechanisms in recipient cells of the primary and secondary tumor microenvironment of ovarian cancer was induced after the uptake of ovarian cancer-released exosomes.

Keywords: ovarian cancer, exosome, reactive oxygen species, proliferation, phosphokinase signaling

\section{OP-44}

\section{EVALUATION OF THE CYTOTOXIC EFFECT OF THE COMBINATION OF CARBOPLATIN AND CARVACROL}

Cağatay Oltulu ${ }^{1}$, Melek Akıncı², Elvan Bakar ${ }^{3}$

${ }^{1}$ Department of Pharmaceutical Toxicology, Faculty of Pharmacy, Trakya University, Edirne, Turkey

${ }^{2}$ Department of Pharmacology, Faculty of Pharmacy, Trakya University, Edirne, Turkey

${ }^{3}$ Department of Basic Pharmaceutical Sciences, Faculty of Pharmacy, Trakya University, Edirne, Turkey
Objective: Carboplatin is a platinum-based antineoplastic agent. Carvacrol is a phenol with cytotoxic properties. In our study, it was aimed to evaluate the cytotoxic effect of carboplatin and carvacrol in combination with neuroblastoma IC50 dose for 24 hours on astrocyte and neuroblastoma cell lines.

Method: 24 hour IC50 values were determined by MTT test. Neuroblastoma IC50 value was applied to both astrocyte (C8D14) and neuroblastoma (N1E-115) cell lines. Topoisomerase 1 (TOP1), topoisomerase 2 (TOP2), p53, caspase 3 (CAS3), caspase 9 (CAS9) gene expressions were evaluated by qRT-PCR method.

Results: TOP1, TOP2, p53, CAS3 and CAS9 expressions were increased in the astrocyte carboplatin group compared to the control. In the neuroblastoma carboplatin group, p53, CAS3, CAS9 expressions were increased compared to the control. Compared to the astrocyte carboplatin group, TOP1, TOP2, p53 decreased, CAS3, CAS9 increased. CAS3 decreased, p53 and CAS9 increased in the astrocyte cell line in the combination group. In the neuroblastoma line, TOP2, CAS3, CAS9 increased and p53 decreased in the combination group. When carboplatin+carvacrol neuroblastoma and astrocyte group were compared, TOP2, CAS3, CAS9 increased.

Conclusion: The fact that the astrocyte IC50 value was higher than the neuroblastoma value in the carboplatin group indicates the selective effect of carboplatin. In the carboplatin+carvacrol groups, the closeness of the IC50 values indicates that the combination application reduces the target selectivity of carboplatin. mRNA expressions in the carboplatin astrocyte group indicates stress on DNA. In the carboplatin neuroblastoma group, CAS3, CAS9 increase and p53 decrease show that apoptosis occurs. In the combination neuroblastoma group, the increase in TOP2, CAS3, CAS9 and decrease in p53 indicate that apoptosis is triggered, and the significant difference in TOP2, p53, CAS3, CAS9 levels compared to the combination astrocyte group indicates that the effect is still selective.

Keywords: Carboplatin, carvacrol, neuroblastoma, astrocyte, apoptosis, cytotoxicity

\section{OP-45 \\ COMPUTATIONAL METHODS REVEAL POTENTIAL INHIBITORY EFFECTS OF APPROVED DRUGS ON CRAC CHANNELS}

Huseyn Babayev $^{1}$, Ali Şahin ${ }^{1}$, Fatıma Hacer Kurtoğlu², Hüsamettin Vatansev ${ }^{3}$

${ }^{1}$ Selcuk University Faculty of Medicine, Konya, Turkey

${ }^{2}$ Koc University Institute of Health Sciences, Department of Cellular and Molecular Medicine, Istanbul, Turkey

${ }^{3}$ Selcuk University Faculty of Medicine, Department of Biochemistry 
Aim: Calcium signaling and channels play a role in tumor proliferation, invasion, and metastasis. They are also essential for the development of resistance to current cancer therapies. ORAI and STIM proteins form a complex called $\mathrm{Ca} 2+$ release-activated $\mathrm{Ca} 2+(\mathrm{CRAC})$ channels that are the main channels for calcium influx in cancer and immune cells. Overexpression of CRAC channel proteins and their function on activation of cancer-related pathways indicate the potential therapeutic effects of CRAC inhibitors. Therefore, we screened more than 2500 FDA-approved drugs in silico on ORAI proteins to investigate probable inhibitory effects.

Method: AlphaFold server used to obtain the monomeric structures of ORAI1 and ORAI3. Based on previous studies on the crystal structure of Drosophila melanogaster Orai protein, we modeled and refined the $3 \mathrm{D}$ hexa-homomeric structure of the Orai channel. Human The FDA-approved drug library containing 2515 molecules, was obtained from the Selleckchem database. For the prediction of ligand binding pocket, we use the DeepSite webserver based on ANN algorithms. Structure-based virtual screening with docking simulations performed by using the AutoDock Vina tool compiled in PyRx. Ligands with high affinity to target macromolecule used for pharmacophore modeling in Discovery Studio Visualizer.

Findings: Screened molecules were evaluated according to their binding energies $(\Delta G)$. Our results demonstrated that Venetoclax, an antagonist of BCL-2, and Ledipasvir, an antiviral drug, may be used to inhibit ORAI1 and ORAI3, respectively.

Result: These computational drug repositioning studies suggest that several FDA-approved drugs are potent inhibitors of ORAI1/3 and may be an effective solution to cancer progression. By inhibiting ORAI, these repurposed drugs have significant potential for improving cancer treatment efficiency as well as making personalized cancer treatment possible.

Keywords: Calcium release-activated calcium (CRAC), Orai proteins, cancer, drug repurposing.

\section{OP-46 \\ NOVEL POTENTIAL DRUG TARGETS IN KRAS SIGNALING PATHWAYS BETWEEN RIGHT AND LEFT-SIDED COLON CANCERS}

Hatice Cilem Binicier ${ }^{1}$, Asım Leblebici ${ }^{2}$, Ender Berat Ellidokuz ${ }^{1}$, Yasemin Başbınar ${ }^{3}$

${ }^{1}$ Department of Gastroenterology, Faculty of Medicine, Dokuz Eylul University, Izmir, Turkey; Department of Translational Oncology, Institute of Health Sciences, Dokuz Eylul University, Izmir, Turkey

${ }^{2}$ Department of Translational Oncology, Institute of Health Sciences, Dokuz Eylul University, Izmir, Turkey

${ }^{3}$ Department of Translational Oncology, Institute of Oncology, Dokuz Eylul University, Izmir, Turkey
Introduction: According to the WHO, colorectal cancer(CRC) is the third most common cancer in the world. Depending on location, CRCs behave differently in terms of disease progression and overall survival. The aim of the study was to compare gene expression levels between the groups identified by designing an in silico experiment from portals containing publicly available transcriptome data of multiple omic molecular features between right and left-sided CRC.

Method: This study, gene expression data obtained from the primary colon tissue of the patients from the TCGA-COAD database were used. Enrichment analysis was applied to determine the biological processes and signaling pathways of genes whose expression was statistically significantly changed.

Results: The genes in the KRAS signaling pathway were found to be significant according to under-over 65 years old and gender groups. When the gene expressions of the patients' right and left colon tumors were compared according to age and gender, the genes in the KRAS signaling pathway were found to be significant. In the group over 65 years old; CKM, TG, SLC38A3, INSL5, CLDN8 genes; In the group under 65 years old; FGGY, SERPINA10, INSL5 genes; in men; TG, P2RY4, CLDN8, INSL5 genes; in women; TENM2, CKM, FGGY, CLDN8, SLC38A3, INSL5 expression of genes increased in the left colon.

Discussion: Currently, the selection of biologic therapy agents in the treatment of CRC patients and the determination of the response to treatment are limited to the detection of the KRAS mutation. However, it is expected that new molecular markers will enter clinical use with translational research results in the near future. In our study, genomic differences between the genes in the KRAS pathway, which play a role in the development of CRC, according to age and gender, were revealed between right and left CRC.(A.L. is supported by CoHE 100/2000 PhD Scholarships project.)

Keywords: Right-Left colon cancer, KRAS signaling pathway, gene expression

\section{OP-47}

\section{EVALUATION OF PLATELET INDICES IN PATIENTS WITH GYNECOLOGIC TUMORS}

\section{${\text { Abdullah Ercan } \text { Arzuhal }^{1} \text {, Filiz Yarimcan }}^{2}$}

${ }^{1}$ Esenler Medipol University Hospital, Clinical Laboratory, Istanbul, Turkey

${ }^{2}$ Istanbul Medipol University, Department of Medical Microbiology, Istanbul, Turkey

Background: Platelets play a role in the growth, metastatic capacity, and angiogenesis of cancer. This study aimed to compare the change of platelet indices among the patients with a malignant gynecologic disease, those with benign disease, and a control group. 
$3^{\text {rd }}$ International Cancer and Ion Channels Congress 2021

Methods: We included a total of 148 women in the study. The difference between the platelet indices [platelet count (PLT), mean platelet volume (MPV), platelet larger cell ratio (P-LCR), platelet distribution width (PDW), and plateletcrit (PCT)] among the groups were analyzed using KruskalWallis $\mathrm{H}$ test.

Results: Platelet counts were significantly higher in the malignant disease group when compared to the control group, also in the benign disease group when compared to the control group. Platelet counts were also slightly higher in the malignant disease group comparing with the benign disease group. PCT values were significantly higher in the malignant disease group when compared to the control group. There was no difference in MPV and P-LCR values among the groups. Although not statistically significant, PDW values were lower in the malignant disease group when compared to the benign disease and the control groups.

Conclusions: Among platelet indices, PLT and PCT can be used as supporting parameters in predicting the presence of gynecologic tumors. We recommend the use of the increase of PLT and PCT in the diagnosis of gynecologic cancers.

Keywords: Gynecologic cancers, PLT, PCT

\section{OP-48}

\section{A NEW AGENT FOR TREATMENT OF BREAST CANCER: THIO ANTHRAQUINONE MOLECULE}

Yesim Muge Sahin, ${ }^{1}$, Funda Ozkok ${ }^{2}$, Zuhal Hamurcu $^{3}$, Sinem Ortaboy $^{4}$, Vasfiye Hazal Ozyurt ${ }^{5}$

${ }^{1}$ Istanbul Arel University, ArelPOTKAM (Polymer Technologies and Composite Application and Research Center), Istanbul, Turkey

${ }^{2}$ Istanbul University-Cerrahpaşa, Faculty of Engineering, Organic Chemistry, Istanbul, Turkey

${ }^{3}$ Erciyes University, Medicine Faculty, Medical Biology, Betül Ziya Eren Genome and Stem Cell Center, Kayseri, Turkey

${ }^{4}$ Istanbul University-Cerrahpaşa, Faculty of Engineering, Physical Chemistry, Istanbul, Turkey

${ }^{5}$ Mugla Sitk1 Kocman University, Faculty of Tourism, Mugla, Turkey

Aim: Triple negative breast cancers (TNBCs), a highly aggressive and metastatic form of BC, continue to be a clinical problem due to lack of effective targeted therapeutics, owing to its limited sensitivity to chemotherapeutics and aggressive behavior. Therefore, novel molecular targets and treatments are needed to identify for eliminating or controlling TNBC.

For this pupose, a novel Thio Anthraquinone molecule has been synthesized and characterized detailly. In order to understand the electron transfer mechanism and its anticancer activity. the redox behavior of 1-(1-hydroxybutan-2-ylthio) anthracene-9,10-dione has been studied. In the present study, the electron transfer mechanism of this molecule has been investigated using both cyclic voltammetry $(\mathrm{CV})$ and square wave voltammetry (SWV) techniques in DMSO containing 0.1 M TBAPF6 electrolyte system.

Methods: The effects of the synthesized molecule on colony formation of MDA-MB-231 cells with clonogenic assay. Electrochemical experiments were carried out using a Gamry REFERENCE 600 potentiostat/galvanostat with a three-electrode configuration system. A glassy carbon electrode (GCE) (in $3 \mathrm{~mm}$ diameter) used as the working electrode, platinum wire served as the counter electrode and $\mathrm{Hg} / \mathrm{Hg} 2 \mathrm{Cl} 2(0.1 \mathrm{M})$ utilized as the reference electrode. The polar aprotic solvent (DMSO) containing 0.1 M TBAPF6 electrolyte system was used as the supporting electrolyte. The determination of potential range and the effect of scan rates were optimized to obtain stable results.

Results: The treatment of synthesized molecule and its nanoparticle form (10-100 $\mu \mathrm{M})$ led to a significant reduction in the number of colonies MDA-MB-231 compared to NT. The electrochemical results show that 1-(1-hydroxybutan2-ylthio) anthracene-9,10-dione undergoes successive two one-electron reduction to give semiquinone $(\mathrm{A} \bullet-)$ and then quinone dianion (A2-) showing two reversible peaks at low scan rates. However, for higher scan rates, a new redox couple arose at less negative potential whereas the second cathodic peak was gradually dissappearing. This phenomenon was attributed to the formation of ECE mechanism on the electrode surface.

Conclusion: We suggest that our purposefully synthesized molecule may be as a potential anticancer agent that suppresses proliferation of TNBC cells. A close similarity was observed in the electrochemical results of anthraquinone comparing to those of anthracycline drugs which are generally used as therapeutic agents for human cancer diseases.

Keyword: thio anthraquinone, breast cancer, antitumor, biological activity.

\section{OP-49 \\ RADIOTHERAPY EMERGENCIES IN ADULTS: SINGLE CENTRE EXPERIENCE WITH 316 PATIENTS FROM TURKEY}

\section{Alparslan Serarslan}

Ondokuz Mayis University, Faculty of Medicine, Radiation Oncology Department, Samsun, TURKEY

Background and Aim: Radiotherapy (RT) is one of the most important treatment modality for oncological emergencies. The aim of this study is to determine the characteristics and outcomes of emergency RT consultations in Turkey.

Methods: Between 2014 and 2020 years, the written and electronic information of the adult patients who were evaluated for emergency RT $(n=316)$ were reviewed and analyzed, retrospectively. 
$3^{\text {rd }}$ International Cancer and Ion Channels Congress 2021

Results: RT emergencies $(n=316)$ constituted $0.4 \%$ of the adult patients $(n=6991)$ evaluated for RT. Male $(n=215$; $68 \%)$ to female $(\mathrm{n}=101 ; 32 \%)$ ratio was 2.1 . The median age was $61.50 \pm 12.78$ (range, 22-88) years and the most common $(\mathrm{n}=192 ; 60.8 \%)$ age range was between 18 64 years. Most of the emergency RT consultations were requested from the non-emergency departments $(n=246$; $77.8 \%)$, on weekdays $(\mathrm{n}=305,96.5 \%)$, on non-Friday working days ( $\mathrm{n}=249 ; 78.7 \%)$, and between 07:00-15:00 hours $(n=255,80.7 \%)$. Most of the patients had diagnosis of malignancy $(n=315 ; 99.7 \%)$, polimetastases $(n=272$; $86.1 \%)$, comorbid disease $(n=202 ; 63.9 \%)$ and high Zubrod performance status $(n=274 ; 86.7 \%)$. The most common primary cancer site and type were the thorax $(n=158 ; 50 \%)$ and non-small cell lung cancer $(n=116$; $36.7 \%$ ), respectively. Palliation was the most common $(\mathrm{n}=297 ; 94 \%)$ request for emergency RT consultations. And, the palliative RT request was most often $(n=206$; $65.2 \%$ ) for the central nervous system. RT was applied to $81 \%(n=256)$ of emergency RT consultations. RT was most commonly applied for palliative purposes $(n=237 ; 75 \%)$ and to the metastases $(\mathrm{n}=211 ; 66.8 \%)$. It was determined that $80 \%$ of the patients evaluated for emergency RT died within the first 90 days after consultation. Male gender and high Zubrod performance score were associated with poor survival. And, the median survival was $33 \pm 8.10$ (range, 0-1132) days.

Conclusion: RT emergencies are usually treated with palliative intent due to the advanced-stage disease and overall survival of this specific oncological emergencies is poor.

Keywords: Emergency, emergency radiotherapy, oncology, radiotherapy

\section{OP-50}

VITAMIN D AND THE RISK OF CANCER IN TYPE 2 DIABETES MELLITUS PATIENTS

$\underline{\text { Mehmet Emin Arayıcı }}{ }^{1}$, Femin Yalçın², Yasemin Başbınar ${ }^{3}$, Hülya Ellidokuz ${ }^{4}$

${ }^{1}$ Institute of Health Sciences, Department of Preventive Oncology, Dokuz Eylul University, Izmir, Turkey

${ }^{2}$ Department of Engineering Sciences, Faculty of Engineering and Architecture, Izmir Katip Celebi University, Izmir, Turkey

${ }^{3}$ Institute of Oncology, Department of Translational Oncology, Dokuz Eylul University, Izmir, Turkey

${ }^{4}$ Institute of Oncology, Department of Preventive Oncology, Dokuz Eylul University, Izmir, Turkey

Objective: There is growing evidence that diabetes mellitus (type 2) (T2DM) is linked to a higher risk of cancer progression. Apart from the risk factors that are common to both illnesses, diabetes-related characteristics such as hyperinsulinemia, insulin resistance, hyperglycemia, and low-grade chronic inflammation are critical. Vitamin D insufficiency has recently been linked to the development of a number of illnesses, including T2DM and cancer. The goal of this research is to figure out what molecular pathways vitamin D insufficiency may use to promote to tumor progression in T2DM patients.

Method: A search was conducted following the preferred reporting techniques for systematic reviews and database analysis. In July 2021, a computer research structured on PubMed/Medline, Web of Science, and Scopus was conducted with the main search terms "Vitamin D", "T2DM" and "cancer" for studies evaluating in cancer.

Results: Vitamin D lowers diabetes-related cancer risk factors by reducing insulin resistance, hyperglycemia, oxidative stress, and inflammation. Vitamin D also improves DNA repair and controls cancer cell apoptosis and autophagy, and otherwise signal transduction pathways implicated in carcinogenesis, such as "tumor growth factor (TGF)", "insulin-like growth factor (IGF)", and "Wnt-BCathenin". Vitamin D metabolism and activity have been changed in many types of cancer cells as a consequence of Vitamin D Receptor (VDR) and CYP27B1 expression dysregulation, which should be recognized. Although several research have demonsrated that appropriate vitamin D levels prevent or postpone the development of T2DM and several cancer, nothing is known about how the vitamin influences cancer risk in T2DM patients.

Conclusion: Randomized clinical studies are urgently needed to determine if vitamin D insufficiency is a factor in the increased risk of cancer in T2DM patients, and whether supplementing with the vitamin by people with diabetes and cancer might enhance cancer prognosis and diabetes metabolic management.

Keywords: cancer prognosis, type 2 diabetes (T2DM), vitamin D

\section{OP-51 \\ ENERGY METABOLISM CHANGES IN THE MULTIPLE MYELOMA CELL LINE}

Hakan Boyunağa ${ }^{1}$, Neslihan Genișel ${ }^{2}$, Hikmet Taner Teker ${ }^{1}$, Mesut Ortatatl1 ${ }^{2}$, Levent Kenar ${ }^{2}$

${ }^{1}$ Departmant of Medical Biochemistry, Faculty of Medicine, Ankara Medipol University, Ankara, Turkey

${ }^{2}$ Departmant of Medical CBRN, Institute of Gulhane Health Sciences, University of Health Sciences, Ankara, Turkey

Cancerous cells obtain the energy required for increased protein synthesis and cell divisions mainly from glucose and glutamine sources. Glycolysis is the common pathway used by normal or cancerous cells to obtain ATP. However, cancerous cells have the ability to change their metabolism according to the oxygen and glucose concentration of the environment. 
The conversion of aerobic glycolysis to anaerobic glycolysis according to the oxygen concentration of the environment and, as a result, the breakdown of more storage glycogen in order to provide the energy needed by the cells is called the Pasteur effect. The pasteur effect is observed in cancerous cells as well as in normal cells. However, in cancerous cells, there is another metabolic pathway called the Crabtree effect, which is dependent on the substrate concentration. In this pathway, the anaerobic glycolytic pathway comes to the fore when the substrate concentration is high, while the cancer cell turns to the aerobic pathway when the substrate concentration is low, which reduces the effectiveness of drugs for energy metabolism. In our experimental study, it was planned to investigate the energy metabolism rates and Pasteur or Crabtree effect levels of multiple myeloma cell cultures under aerobic, anaerobic and low glucose conditions. Multiple myeloma cell cultures were divided into aerobic, anaerobic with $\mathrm{KCN}$ addition, and three groups containing low glucose and 7 subgroups each, and their metabolism with radioactive glucose was examined. Radiolabeled D-[6-C14] Glucose was purchased from Amersham (Bucks, UK) and hexokinase and glucose-6phosphate dehydrogenase enzymes were obtained from Boehringer (Manheim, Germany). The human multiple myeloma cell line RPMI-8226 (ATCC-CCL-155 TM) was obtained from Gülhane Health Science Institute, Ankara, Turkey and was grown in RPMI-1640 medium supplemented with $10 \%$ fetal bovine serum, $100 \mathrm{U} / \mathrm{mL}$ penicillin, $100 \mu \mathrm{g} / \mathrm{mL}$ streptomycin, $2 \mathrm{~g} / \mathrm{L}$ glucose and $0,3 \mathrm{~g} / \mathrm{L}$ Glutamine maintained at $37^{\circ} \mathrm{C}$ in an atmosphere containing 5\% CO2. For low glucose medium RPMI-1640 medium without glucose was used. Glycogen consumption, $\mathrm{CO} 2$ and lactate productions were compared between aerobic and anaerobic normal leukocyte cultures and RPMI-8226 human myeloma cell cultures. Aerobic RPMI8226 human myeloma cell culture had higher glycogen consumption and labelled lactate production compared to aerobic leucocyte culture $(\mathrm{p}<0.01)$. Glycogen consumption and labelled lactate production were significantly higher in anaerobic leukocyte culture and anaerobic RPMI-8226 human myeloma cell culture compared to their aerobic counterparts. ( $p<0.01$ for all comparisons). In low glucose medium lactate production decreased and $\mathrm{CO} 2$ production increased in RPMI-8226 human myeloma cell culture compared to one in normal glucose medium. Data from this study showed that when oxygen use of multiple myeloma cell cultures was prevented by adding $\mathrm{KCN}$ into the culture media which blocks electron transport chain in aerobic glycolysis thus creating anaerobic condition, glycogen consumption and lactate production increased and $\mathrm{CO} 2$ production decreased. On the other hand, when substrate concentration of the culture medium was reduced, increase in $\mathrm{CO} 2$ production and decrease in glycogen consumption and lactate production were observed indicating aerobic glycolysis rate was increased.

In conclusion, it was observed that human multiple myeloma cell lines show both Pasteur and Crabtree Effects.
Keywords: cancer, energy metabolism, pasteur effect, craptree effect

\section{OP-52 \\ BORNYL ACETATE AND 6-GINGEROL PRESENT CYTOTOXIC AND APOPTOTIC EFFECT ON HUMAN BREAST CANCER CELLS AND HUMAN BREAST CANCER STEM CELLS}

Özlem Tomsuk ${ }^{1}$ Sedat Kaçar $^{2}$, Varol Şahintürk ${ }^{1},{ }^{2}$ Ayla Eker Sariboyac1 $^{3}$

${ }^{1}$ Eskişehir Osmangazi University, Graduate School of Natural and Applied Sciences, Biotechnology and Biosafety Department, Eskişehir

${ }^{2}$ Eskişehir Osmangazi University, Faculty of Medicine, Department of Histology and Embryology, Eskişehir.

${ }^{3}$ Eskişehir Osmangazi University, Cellular Therapy and Stem Cell Production Application and Research Center, Eskişehir

Purpose: Cancer accounts for almost 8.2 million deaths every year worldwide. For this reason, cancer treatment is becoming increasingly important as a research issue and new drug discovery continues being a hot topic. Novel pharmaceutical products from natural active components have been increasing in recent years and used in the cancer treatment. In this respect, the anticancer effect of bornyl acetate (BA), which is one of the main components of Inula species, which is also endemic in our country, and its synergistic effect with 6- gingerol (6G) was investigated in MCF7 (breast cancer cell line) and breast cancer stem cells.

Materials and Methods: In the present study, cytotoxicity, apoptotic effect and cell morphology was revealed. Then, immunocytochemical examinations (Bax and Bcl-2, proand anti-apoptotic markers) were implemented. For this purpose, MCF7 cells and breast cancer stem cells isolated from MCF7 cells by MACS method which is a magnetic cell separation technique, were plated into $75 \mathrm{~cm} 2$ flasks in a ready-to-use medium supplemented with fetal bovine serum and penicillin-streptomycin in an incubator at $37^{\circ} \mathrm{C}$ with $5 \%$ CO2. After sufficient confluency (70-80\%) was achieved, the cells were removed from flasks with trypsinEDTA and plated into 96 well-plates. After $24 \mathrm{~h}$ treatment, the cells were incubated with various concentrations of BA, $6 \mathrm{G}$ and BA/6G ranging from 0-600 $\mu \mathrm{M}$. $24 \mathrm{~h}$ later, MTT cytotoxicity assay was applied to determine the inhibitory effect of BA and $6 \mathrm{G}$ for 24, 48 and $72 \mathrm{~h}$. Furthermore, the cells were treated with IC50 of BA and $6 \mathrm{G}$, and $\mathrm{H} \& \mathrm{E}$ staining was performed for the observation of cell morphology. Then, the effect of apoptosis by BA and 6G was investigated by acridine orange/ethidium bromide (AO/ EB) staining, Annexin V/PI and immunocytochemistry staining. 
$3^{\text {rd }}$ International Cancer and Ion Channels Congress 2021

Results: Our MTT results showed that the BA, 6G and $\mathrm{BA} / 6 \mathrm{G}$ treatment has cytotoxic effect in a dosedependent manner on MCF7 and breast cancer stem cells and the IC50 value was determined. In H\&E staining, we observed apoptotic bodies, vacuolization, swelling, nuclear condensations and other cellular degenerations on the cells. Furthermore, the characteristics of apoptotic morphology such as cytoplasmic blebbing and shrinkage of the cells and nuclear condensation was showed using the method of $\mathrm{AO} / \mathrm{EB}$ staining. In Annexin V/PI staining, the percentage of apoptotic cells was found about $40 \%$ in both cell types at IC50 value for $24 \mathrm{~h}$. Additionally, increased Bax and reduced Bcl-2 expression was observed in immunocytochemistry examination upon test compounds treatment at $24 \mathrm{~h}$.

Conclusion: BA, $6 \mathrm{G}$ and $\mathrm{BA} / 6 \mathrm{G}$ exhibited the cytotoxic and apoptotic effect and morphological changes on MCF7 human breast cancer cells and breast cancer stem cells. Therefore, the potency of BA and $6 \mathrm{G}$ for being anticancer agent ought to be examined in detail in future studies.

Keywords: Bornyl acetate, 6-gingerol, MCF7 breast cancer cells, breast cancer stem cells, cytotoxicity, apoptosis.

\section{OP-53}

\section{ANATOLIAN SCORPION VENOM PEPTIDES PROMISE FOR CANCER TREATMENT BY TARGETING ION CHANNELS}

Özlem Tomsuk ${ }^{1},{ }^{4}$, Gülșah Tekatll ${ }^{2}, 5$, Ceren Şenel $^{3}$

${ }^{1}$ Turk İlaç ve Serum Sanayi A.Ş., Antisera Production Department, Ankara

${ }^{2}$ Turk İlaç ve Serum Sanayi A.Ş., Quality Assurance Department, Ankara

${ }^{3}$ Turk İlaç ve Serum Sanayi A.Ş., Regulatory Affairs Department, Ankara

${ }^{4}$ Eskişehir Osmangazi University, Graduate School of Natural and Applied Sciences, Biotechnology and Biosafety Department, Eskişehir,

${ }^{5}$ Ankara University, Graduate School of Natural and Applied Sciences, Department of Biology, Ankara

Purpose: Venom peptides obtained from animals such as scorpions, snakes, spiders and bees have been used in traditional medicine, and now these peptides are widely used in pharmaceutic biotechnological research. In recent years, there are animal peptides used in the clinical treatment of diseases such as hypertension (Captopril (Teprotide)), chronic pain ( $\omega$-Conotoxin MVIIA (Ziconotide), Prialt ${ }^{\circledR}$ ) and diabetes (Exenatide Byetta $\AA$ ), approved by the American Food and Drug Administration (FDA). It has been revealed that animal peptides have anticancer activity in line with recent studies. Purified from scorpion venoms Chlorotoxin, BmK AGAP, BmKCT, Iberiotoxin, Magatoxin, Charybdotoxin, Bengalin, Neopladin 1 and 2 peptides are current peptides under development in cancer treatment. Chlorotoxin is a long scorpion-derived peptide under development in the treatment of Glioma. Scorpion venom peptides are known to inhibit cell proliferation and metastasis, increase caspase activation and lead the cell to apoptosis, by targeting ion channels. Since scorpion venom peptides contain molecules specific to each species, they show activity by selectively binding to ion channels. It has been revealed that Chlorotoxin, which is produced recombinantly, has antiangiogenic effects, and it is a molecule that plays a role in the imaging of cancerous cells. Scorpion peptides are molecules that differ depending on each species. Structurally, it is species specific. Therefore, our country's scorpion peptides are a treasure of undiscovered new and native molecules. Herein, we compiled these agents and their effects shown in in vivo or in vitro studies.

Methods: We used the search engines of Web of Knowledge and NCBI Pubmed. In this respect, we searched the keywords "scorpion venom and anticancer effect" and "scorpion venom and ion channel" in the titles.

Results: Approximately, sixteen related articles were examined. Briefly, all agents used about anticancer effect of scorpion venom peptides were reported.

Conclusion: Finally, we reported that investigation of the effect of scorpion venom components is important in terms of revealing new and locally designed molecules for the treatment of many diseases, especially cancer. It is our goal to improve in biotechnological drugs to our country. In the future, we aim to obtain molecules that will benefit not only our country but also all humanity and contribute to Turkey economically.

Keywords: Scorpion toxins, venom peptides, ion channel, anticancer peptides, drug discovery.

\section{OP-54}

ANTICANCER ACTIVITY AND DRUGLIKENESS OF NOVEL B-HYDROXYKETONES: AN IN SILICO STUDY

Ahmet Mesut Șentürk $^{1}$, Mustafa Güzel², Hatice Başpınar Küçük ${ }^{3}$, Gökhan Kantürk ${ }^{4}$

${ }^{1}$ Istanbul Biruni University Department of Pharmeceutical Chemistry, Faculty of Pharmacy, 34010 Topkap1, Istanbul Turkey

${ }^{2}$ Istanbul Medipol University, Research Institute for Health Sciences and Technologies (SABITA), Center of Drug Discovery and Development, Kavac1k-Beykoz/Istanbul, 34810, Turkey

3cIstanbul Medipol University, International School of Medicine, Department of Medical Pharmacology, Kavacik Campus, Kavacik-Beykoz/ISTANBUL 34810, Turkey 4dIstanbul UniversityCerrahpasa, Faculty of Engineering, Department of Chemistry, Organic Chemistry Division, Avc1lar/ISTANBUL 34320, Turkey 
$3^{\text {rd }}$ International Cancer and Ion Channels Congress 2021

In this study, a series of novel $\beta$-hydroxy ketone derivatives were designed, and investigated with molecular docking studies for their anticancer effects against breast cancer and acute myeloid leukemia (AML). Docking studies were performed by the usage of Autodock 4.2.6.

Antiproliferative effects of these novel compounds have been investigated withmolecular docking studies and the bestdocked poses of the molecules have been throughly evaluated. The best binding affinity and receptor/ligand interaction of every compound has been assessed and wellestablished good interactions of compounds withinside the receptor's active pocket of the target receptor proteins have been visualized by the use of Python Molecular Viewer 4.2.6.

Based on the previous research of similar structures possessing aryl hydroxy ketone derivetives we have decided to look for possible binding motifs for estrogen receptor in order to investiagate their anticancer activity forbreast cancer and Acute Myloid Leukemia (AML). We compared our results with often used anticancer medicines Tamoxifen and Doxorubicin.

The conformation with the reasonably low docking energy scores are chosen after the docking interactions because lowest negative binding energy values indicate the most powerful binding capability of the ligand withinside the target. Nearly all the compounds confirmed appropriate binding free energies towards FLT3 and Estrogen Receptors. Our compounds bonded to the active site and overlapped with reference compounds. Our preliminary results showed that these compounds demonstrate reasonably good ligandreceptor binding interactions to better understand structureactivity relationships of compounds, drug-likeness rankings have been calculated through the usage of Swiss ADME Calculation program. The molecular weight, $\log$, TPSA, crossing the BBB, GI absorption properties and sort of CYPP450 inhibition type of compounds have been provided. Nearly all compounds have been discovered to have relatively affordable values which will pass the lipid barriers.

Keywords: $\beta$ hydroxy ketone, keto alcohol, anticancer activity, docking, molecular modelling studies 